\title{
Hábitos de consumo de Facebook y YouTube. Conciencia y estrategias metacognitivas en la lectura y estrategias de aprendizaje y estudio en universitarios*
}

Fernando Gabriel Ruiz Dodobara \& Luis Miguel Escurra Mayaute Universidad de Lima

Recibido: 5 de abril del 2013 / Aprobado: 4 de julio del 2013

Se estudió la relación entre el uso de las plataformas en línea Facebook y YouTube, la conciencia metacognitiva, las estrategias metacognitivas en la lectura y las de aprendizaje y estudio en 463 estudiantes de primeros ciclos en cuatro universidades privadas y una estatal, varones y mujeres (16-23 años). Se desarrollaron escalas para las variables estudiadas y para analizar los hábitos de consumo de plataformas en línea, que presentaron validez y confiabilidad. Los resultados indicaron un mayor uso de la plataforma en línea Facebook, así como bajos niveles en el desarrollo de la conciencia metacognitiva y en el uso de estrategias metacognitivas en la lectura.

metacognición / estrategias / lectura / aprendizaje y estudio

Habits of consumption in Facebook and YouTube. Metacognitive conscience and strategies in reading, and learning and study strategies in university students

The study focused on the relationship between the use of online platforms (Facebook and Youtube), metacognition awareness, metacognitive reading strategies and learning and study strategies. The study used a sample of 463 first year students from four private and a public university, men and women between 16 and 23 years old. The authors developed scales to measure the study variables and to analyze the consumption habits of online platforms. The instruments showed validity and reliability. The results indicated a greater use of the online Facebook platform, low levels of metacognitive awareness and low levels of metacognitive reading strategies.

metacognition / strategies / reading / learning and study

* Estudio realizado con el auspicio del Instituto de Investigación Científica de la Universidad de Lima.

Correo electrónico: Fruizd@ulima.edu.pe 


\section{INTRODUCCIÓN}

Las plataformas en línea tipo Facebook se desarrollan desde el 2004 (Sheldon, 2008). Facebook constituye una de las redes sociales de más rápida expansión, con millones de usuarios. Por otro lado, cada día, millones de televidentes ingresan a YouTube para ver y compartir videos (Chau, 2010). Ambas plataformas son algunos de los productos en línea más populares entre los universitarios (Castañeda, 2010).

El uso continuo de internet está teniendo efectos en nuestra manera de procesar la información. Existe evidencia sobre la influencia de internet en la atención (Yoo et al., 2004), sobre la reflexión superficial acerca de lo que se lee en el mundo virtual (Carr, 2011) y sobre la preferencia en los jóvenes por contenidos interactivos en desmedro de contenidos presentados de una manera tradicional, tipo los textos escritos (Livingstone, 2009).

Un componente vital para el éxito académico es la metacognición. Esta supone la conciencia y reflexión sobre la propia cognición, y el control de la atención y de los procesos mentales en general para lograr metas de aprendizaje (Woolfolk, 2010). Dado que la metacognición implica la autorregulación del estudiante y la reflexión sobre su propia cognición y los contenidos que procesa, consideramos necesario esclarecer la relación entre la metacognición para la vida académica y el consumo de plataformas en línea tipo Facebook y YouTube.

\section{LA ATENCIÓN}

Un componente indispensable para cualquier estrategia cognitiva o metacognitiva es la atención, que es un requisito primordial para el aprendizaje. La atención permite pasar la información que llega a nuestros sentidos de la memoria a corto plazo a la de largo plazo, de lo contrario esta información sería olvidada (Woolfolk, 2010).

La atención puede ser definida como el medio que permite procesar una fracción limitada de toda la información a la que se tiene acceso por medio de los recuerdos almacenados, los sentidos y otros procesos cognitivos (Sternberg, 2011). Pozo (1996) recuerda que la atención desempeña tres funciones: como sistema de filtro o selección de la información que es procesada, como mecanismo de vigilancia y alerta (permite mantener la atención), y como sistema de control de recursos limitados.

Respecto a las actividades que demandan atención es importante distinguir entre las que implican procesos controlados y procesos automáticos. Los procesos automáticos requieren muy poco o ningún esfuerzo intencional; generalmente ocurren fuera de la conciencia y gastan pocos recursos de atención, son rápidos, se efectúan de acuerdo con un procesamiento en paralelo (muchas operaciones ocurren al 
mismo tiempo sin un orden en particular), implican un bajo nivel de procesamiento cognoscitivo (síntesis y análisis a niveles mínimos) y suponen tareas bastante sencillas. Por el contrario, los procesos controlados demandan esfuerzo intencional, requieren una alta conciencia acerca de lo que se está haciendo, suponen el uso de muchos recursos atencionales, se efectúan en forma serial (un paso a la vez), llevan mucho tiempo en comparación con los procesos automáticos, suponen tareas novedosas o difíciles e implican niveles elevados de procesamiento cognitivo (análisis y síntesis). Es importante resaltar que, normalmente, podemos desarrollar al mismo tiempo varias conductas automáticas, pero que es difícil participar en más de una tarea controlada (Sternberg, 2011).

La teoría de recursos atencionales limitados explica por qué las personas no podemos atender dos tareas complejas o controladas al mismo tiempo. Esta teoría desarrollada por Kahneman (2011) sostiene que los individuos disponemos de una cantidad fija de atención que podemos asignar a una tarea. Hay tareas, como leer un libro, que demandan procesos controlados y, por ende, gastan muchos recursos atencionales. Asimismo, si realizamos tareas automatizadas o si convertimos procesos controlados en automatizados invertiremos pocos recursos atencionales. Podemos hacer varias tareas automatizadas al mismo tiempo o acompañar la realización de tareas complejas con tareas automatizadas. De lo anterior se infiere que dos tareas complejas que demandan considerables recursos atencionales se obstaculizan entre sí (Pozo, 1996). Se ha comprobado que la atención dividida en dos tareas difíciles de realizar producen un detrimento en el desempeño de ambas. En resumen, si dos tareas demandan recuperar un dato de la memoria, elegir una respuesta o desarrollar otras operaciones cognoscitivas, es muy posible que las actividades se interfieran mutuamente (Sternberg, 2011).

\section{EstRATEGIAS COGNITIVAS $Y$ METACOGNITIVAS}

Las estrategias de aprendizaje constituyen un conjunto de conductas y pensamientos que los alumnos utilizan durante el proceso de aprendizaje, los cuales tienen por finalidad modificar sus procesos de codificación influyendo en los estados motivacionales y afectivos, especialmente en la manera en que se seleccionan, adquieren, organizan o integran los nuevos conocimientos (Weinstein \& Mayer, 1986). Entre las estrategias de aprendizaje podemos encontrar las estrategias cognitivas y las metacognitivas.

Las estrategias cognitivas aluden a la integración del nuevo material con el conocimiento previo. En este sentido, serían un conjunto de estrategias que se utilizan para aprender, codificar, comprender y recordar la información 
al servicio de unas determinadas metas de aprendizaje. Dentro de este grupo se distinguen a su vez tres clases de estrategias: a) la estrategia de repetición consiste en pronunciar, nombrar o decir en forma repetida los estímulos presentados dentro de una tarea de aprendizaje. Se trataría, por tanto, de un mecanismo de la memoria a corto plazo que transfiere contenidos a la memoria a largo plazo; b) la estrategia de elaboración trata de integrar los materiales informativos relacionando la nueva información con la ya almacenada en la memoria, y c) la estrategia de organización intenta combinar los elementos informativos seleccionados en un todo coherente y significativo.

Además, dentro de esta categoría de estrategias cognitivas también estaría la estrategia de selección o esencialización, cuya función principal es la de seleccionar aquella información más relevante con la finalidad de facilitar su procesamiento (Weinstein \& Mayer, 1986).

Las estrategias metacognitivas hacen referencia a la planificación, el control y la evaluación por parte de los estudiantes de su propia cognición. Son un conjunto de estrategias que permiten el conocimiento de los procesos mentales, así como el control y regulación de estos con el objetivo de lograr determinadas metas de aprendizaje. La metacognición supone dos componentes. El primero implica estar consciente de las habilidades, estrategias y recur- sos necesarios para realizar una tarea de forma efectiva (saber qué hacer); un ejemplo del primer componente sería el uso de mnemónicos, la formación de asociaciones, la organización de material nuevo, la identificación de la idea principal, etcétera. El segundo componente supone la capacidad de usar mecanismos autorreguladores para garantizar el éxito de la tarea (saber cuándo y cómo hacer algo); ejemplos de lo anterior son: confirmar si se entendió, planificar el siguiente paso, tomar decisiones sobre la distribución del tiempo y del esfuerzo, etcétera. La utilización de mecanismos autorreguladores es conocida como monitoreo cognoscitivo (Woolfolk, 2010). Por su parte, Reátegui (1996) sostiene que un estudiante metacognitivo tiene el conocimiento acerca de cómo controlar sus procesos de aprendizaje y pensamiento.

Como una muestra de la importancia de la metacognición en el ámbito académico, Pintrich y De Groot (1990) realizaron un estudio con 173 estudiantes de ciencias e inglés de una escuela del sureste de Michigan. Demostraron que la metacognición, entendida como estrategias para planificar, modificar la cognición y monitorear la comprensión (por ejemplo, «me hago preguntas para confirmar que comprendo el material que he estudiado») estaba significativamente relacionada con el uso de estrategias cognitivas tales como el ensayo (por ejemplo, «cuando leo el texto de clase, leo las palabras una y otra vez 
para ayudarme a recordarlas»), la elaboración (por ejemplo, «pongo en mis propias palabras lo que he estudiado») y la organización de material académico. Asimismo, la metacognición guardaba relación con el interés intrínseco por algún tema académico.

\section{LA COMPRENSIÓN LECTORA EN}

ESTUDIANTES UNIVERSITARIOS DE PRIMEROS CICLOS

La importancia de la lectura en el ámbito académico es evidente. La mayor parte del conocimiento disponible se encuentra en materiales escritos, ya sean físicos o virtuales. No obstante, no todos los estudiantes presentan una comprensión lectora adecuada para la vida académica. Según McNamara (2009), los problemas de lectura están relacionados con entender cómo una palabra se integra en una oración. Asimismo, el estudiante puede entender la palabra y la oración, pero fallar en comprender la conexión entre el significado del texto como un todo y como una oración aislada.

Respecto a la problemática de los estudiantes de primer ciclo, Gonzales (1998) distingue tres estrategias para la ejecución lectora: subléxica, léxica y supraléxica. En la estrategia subléxica el lector identifica el valor fonético de los conjuntos de letras deletreando o silabeando, de esta manera se alcanza una decodificación sin comprensión.
En la estrategia léxica, el individuo procesa una por una cada unidad léxica. Este procesamiento solo permite una lenta lectura de comprensión literal, fragmentada, se pasa de la palabra al significado. La tercera estrategia, la supraléxica, se caracteriza por que el sujeto progresa anticipando los significados de las palabras, se consigue así una comprensión inferencial: las palabras y oraciones iniciales activan una red de inferencias que anticipa el material posterior.

Gonzales (1998), en un estudio realizado en Lima con una muestra de estudiantes universitarios de primeros ciclos de dos universidades, una privada (311 estudiantes) y una estatal (41 estudiantes), encontró que la mayoría de sujetos tenía dificultades en la comprensión de textos complejos de temática humanística, literaria y científica: 166 alumnos caen en la categoría «deficiente malo» y 66 en la de «deficiente pésimo», esto supone que la mayor parte de la muestra tiene graves dificultades para la comprensión textual y carece de prerrequisitos para realizar una lectura adecuada. Por lo tanto, se evidencia la ausencia de una adecuada lectura supraléxica.

Esta problemática no es específica del Perú, por el contrario, se encuentra cada vez más generalizada. Profesores universitarios y personal relacionado con la educación declaran que los déficits en lectura y escritura son cada vez 
mayores en los estudiantes y que estos llegan a las aulas sin las habilidades mínimas que se exigen en los centros de enseñanza (Monereo \& Pozo, 2008).

\section{Plataformas en línea y aspectos COGNITIVOS Y METACOGNITIVOS}

Las nuevas tecnologías promovidas por internet poseen una amplia aceptación en la población. Esto se explica en parte porque las computadoras son percibidas como productos positivos ligados a la comunicación (Dancker, 1990), por el fortalecimiento de la identidad que posibilitan las redes sociales (Ruiz, 2006) y por la visión de los ordenadores como aparatos amigables que suponen riesgos mínimos y controlables (Slovic, 1987). Se debe recalcar que este uso masivo de las computadoras y los productos en línea estaría afectando nuestros hábitos de consumo de información, la forma en que aprendemos y nuestro control para mantener una atención sostenida (Carr, 2010).

Se plantea que el uso de las nuevas tecnologías de la información y la comunicación (TIC) constituye un gran aporte en el campo de la enseñanza y el aprendizaje (Cebrián, 2011). Comúnmente se sostienen tres beneficios de las TIC en la educación: 1) ayudan a compensar desventajas en el aprendizaje, 2) permiten nuevos resultados en el aprendizaje, y 3) ayudan al aprendizaje tradicional. Sin embargo, la realidad nos muestra evidencias contrastantes. Así, Thomas y Ludger (2004, en Li- vingstone, 2009) realizaron un estudio en el que se relacionaron las variables disponibilidad de computadoras (en el hogar y la escuela) y rendimiento escolar. El estudio demostró que una vez controladas las variables educación familiar y características de la escuela, el rendimiento escolar y la disponibilidad de una computadora en casa se relacionan de manera negativa. Por otro lado, el rendimiento escolar y la disponibilidad de una computadora en el colegio no mostraron relación significativa alguna. A la vez, se demostró que los estudiantes que, eventualmente, usaban computadoras o internet en la escuela se desempeñaban mejor que los que nunca las usaban. No obstante, quienes usaban frecuentemente computadoras e internet se desempeñaban peor que los que nunca las usaban. En otro estudio, Thiessen y Looker (2007, en Livingstone, 2009) analizaron si el aprendizaje de tareas de software educativo se transfería positivamente a la capacidad de lectura. Se encontró que para los canadienses mayores de 15 años un mayor uso de las TIC estaba relacionado con una mejora en los puntajes de lectura hasta cierto punto, pasado ese punto un mayor uso de las TIC se asociaba con puntajes más bajos.

Por su parte, Yoo y colaboradores (2004) encontraron que el excesivo uso de internet puede estar relacionado con el grado de intensidad del síndrome de atención deficitaria e hiperactividad. Los investigadores realizaron un traba- 
jo con 535 niños de escuela primaria en Corea, para lo cual utilizaron el test de Young de adicción a internet. Se pidió a los padres y a los profesores que llenaran el test de atención deficitaria e hiperactividad (ADHD en inglés) y listas de chequeo relacionadas con el comportamiento de los estudiantes. Cinco niños presentaron adicción a internet comprobada y 75 fueron catalogados con una posible adicción a la red. Se encontró una correlación positiva entre el test de atención deficitaria e hiperactividad y el test de adicción a internet de Young. El grupo con síndrome de atención deficitaria e hiperactividad tenía índices más altos de adicción a internet en comparación con el grupo que carecía de este síndrome (Yoo et al., 2004).

\section{FACEBOOK Y YouTuBe}

Las redes sociales como Facebook o MySpace se caracterizan por la presentación de «perfiles», una especie de página web personal que ofrece una descripción de cada uno de los miembros de la red social. Además de imágenes, video y texto en cada perfil se pueden apreciar comentarios de otros miembros de la red social y una lista pública de las personas que el dueño del perfil identifica como sus «amigos». Generalmente, en los perfiles se muestra información personal como sexo, edad, localización, intereses, personas a las que el usuario quisiera conocer, etcétera. El perfil es público por defecto, pero las redes sociales pueden establecer opciones de privacidad y limitar la visualización del perfil a determinados usuarios. La red social permite al poseedor de un perfil ver los perfiles de otras personas y enviarles una solicitud de amistad para agregarlos a su lista de «amigos». Si se acepta la solicitud ambas personas tendrán links que conecten sus perfiles y se mostrarán públicamente como amigos a los demás usuarios. Una de las características principales de las redes sociales es una sección dedicada a los comentarios de «amigos». Esta sección, 1lamada «el muro» en Facebook, posibilita a otros usuarios realizar comentarios destinados a una persona, los que pueden ser vistos por todos los «amigos» del dueño del perfil. Cuando varios comentarios se juntan y siguen determinada dirección, a menudo se construyen conversaciones bastante largas (Boyd, 2007).

En tanto, YouTube es una plataforma en línea para compartir videos, permite a sus usuarios compartir gratuitamente sus videos y tener acceso a ver los de otros usuarios. Esta plataforma es uno de los sitios web con mayor popularidad en internet: en enero del 2009 YouTube recibió 100,9 millones de televidentes que presenciaron aproximadamente 6,3 billones de videos. La mayoría de los videos en YouTube son videos cortos de entre 30 segundos y tres minutos cada uno. El grueso de usuarios de YouTube son adultos, no obstante, los adolescentes de entre 17 y 19 años representan el $17 \%$ de los usuarios. En un estudio 
realizado por Entertainment Media Research en el 2009, se encontró que los adolescentes utilizaban YouTube para pasar el tiempo, entretenerse, mirar videos, ver lo que otras personas estaban comentando y para seguir recomendaciones de amigos. También se encontró que la mitad de los adolescentes encuestados expresaron que se registraban en YouTube para volverse miembros y poner comentarios y $17 \%$ declararon que se registraron para crear su propio canal de YouTube (una página web en la que los usuarios pueden mostrar contenidos creados por ellos mismos). La plataforma YouTube se estructura de acuerdo con la participación de los visitantes. Las bases de datos toman en cuenta las veces que un video ha sido visto y muestran el número de vistas. Los videos más vistos son mostrados en la página de inicio de YouTube. Por otro lado, los comentarios sobre los videos son presentados debajo de cada video. Los usuarios que responden más rápido los comentarios generados por «fans» tienen más posibilidad de ganar más suscriptores y más vistas a sus videos (Chau, 2010).

\section{EL USO dE LAS PLATAFORMAS EN LÍNEA, LA METACOGNICIÓN Y EL APRENDIZAJE}

Para entender cómo las plataformas Facebook y YouTube modifican la cognición de los individuos es necesario considerar la perspectiva vigotskiana, la cual plantea que las herramientas con las que operamos el medio ambiente, además de transformar el entorno transforman nuestras prácticas $\mathrm{y}$, por ende, la manera en que pensamos. Las TIC se usan en el día a día y se conectan directamente con los procesos de comunicación y aprendizaje, por consiguiente, estarían dando a la mente un nuevo formato (Monereo \& Pozo, 2008).

También debemos tener en cuenta el cambio de lo escrito a lo visual. Lo escrito ya no es el único medio para transmitir todo tipo de información, existen otras actividades que funcionan como mediadoras del aprendizaje: diseñar, buscar, jugar, etcétera (Livingstone, 2009). Turkle (1995) sostiene que se ha pasado de una cultura en la que lo importante era entender las reglas de una estructura a una era donde lo que se busca es hacer y experimentar con la interfase virtual.

INFLUENCIA DE LAS PLATAFORMAS EN LÍNEA: ATENCIÓN DIVIDIDA

Tanto en las plataformas virtuales de uso popular (Facebook y Youtube) como en los videojuegos se debe prestar atención simultánea a varios estímulos (Livingstone, 2009).

La práctica de videojuegos demanda una continua atención a elementos cambiantes que aparecen en la pantalla en un corto tiempo. Estos productos promueven una atención visual dividida, 
el procesamiento de gran cantidad de información en tiempo reducido y el deseo de retroinformación inmediata para dirigir las acciones del usuario (Lalueza, Crespo \& Camps, 2008).

Ambos productos (videojuegos y plataformas en línea) refuerzan un tipo de atención que contrasta y afecta negativamente la atención requerida en el ámbito académico. En un estudio de Junco y Cotten (2011) con 1839 estudiantes universitarios estadounidenses, se evidenció el impacto de la multitarea de las tecnologías de la comunicación e información tipo Facebook en el promedio de los estudiantes. Los sujetos declararon que mientras realizaban sus tareas normalmente usaban Facebook, buscaban información no relacionada con sus cursos, mandaban correos electrónicos, hablaban por teléfono y mandaban mensajes de texto. Un análisis regresivo lineal mostró que el uso de Facebook y el mandar mensajes de texto mientras se realizaban los deberes universitarios estaban negativamente relacionados con el promedio de los alumnos. Las habilidades de atención visual dividida que desarrollan los videojuegos y las plataformas en línea son diferentes de la atención que se promueve en la escuela: una atención continua centrada en eventos únicos. Además, en el medio escolar se ofrece la información de manera escalonada, se da preferencia al texto y al lenguaje escrito y, por lo general, se brinda retroinformación a mediano plazo (La- lueza, Crespo \& Camps, 2008).

Procesamiento superficial de LA INFORMACIÓN

Las nuevas tecnologías de internet presentan contenidos que impulsan una comprensión rápida y superficial (Carr, 2011).

La gran mayoría de los videos de las plataformas en línea tipo YouTube no demandan una atención sostenida, son fáciles de entender y duran pequeños lapsos de tiempo (Chau, 2010).

Por otro lado, en el caso de los productos en línea, se puede dejar de lado la calidad del contenido y la confiabilidad de la fuente, para centrarse en otros aspectos. Livingstone (2009) sostiene que los jóvenes juzgan la calidad de una página web en relación con su diseño visual y la oportunidad de interactividad que esta brinda.

Así también, en los jóvenes, el uso de las TIC se relaciona con efectos inmediatos. Facer (en Lalueza, Crespo \& Camps, 2008) realizó una investigación en el Reino Unido sobre el uso doméstico de las computadoras. Se encontró que los sujetos, en su mayor parte adolescentes, no consideraban el uso de los ordenadores para la acumulación del saber; por el contrario, apreciaban las consecuencias inmediatas del uso de las TIC: obtener ayuda en sus tareas, comunicarse y divertirse.

Debemos agregar que la cantidad de tareas simultáneas que el su- 
jeto puede hacer al momento de estar frente al ordenador (chatear, jugar un juego de rol, realizar una asignación universitaria o escolar, etcétera) distribuyen su atención y sus estrategias de resolución. De esta manera, se logran niveles de resolución y comprensión superficiales (Monereo \& Pozo, 2008). Algunas investigaciones nos muestran que lo anteriormente expuesto podría estar relacionado con una falla en la enseñanza para analizar contenidos virtuales. De acuerdo con la encuesta «Children Go Online» del Reino Unido, solo el $33 \%$ de los encuestados entre 9 y 19 años de edad que accedían a internet una vez a la semana declararon haber sido instruidos en cómo juzgar la fiabilidad de la información en línea (Livingstone, 2009).

\section{LA LECTURA EN EL TEXTO Y LA PANTALLA}

En internet la lectura y la escritura se hacen de manera muy diferente a la tradicional: no se realizan de forma lineal sino en paralelo. El hipertexto rompe con el orden de lectura o interpretación del texto tradicional: difícilmente se pueden unificar los fragmentos dispersos y el usuario se encuentra atraído en múltiples direcciones opuestas (Schmar-Dobler, 2003). Respecto a la escritura, las nuevas tecnologías han generado un híbrido entre el lenguaje escrito y el hablado: el lenguaje textual de internet se caracteriza por la brevedad, la falta de atención a la ortografía y por una publicación instantánea de lo escrito sin ningún tipo de revisión formal (Lalueza, Crespo \& Camps, 2008).

Carr (2011) plantea que internet está afectando seriamente nuestra forma de leer. En un estudio realizado en el 2008 por la institución Ngenea sobre los efectos de la red en los jóvenes, se entrevistó a 6000 niños que habían crecido con internet. Los resultados demostraron que ellos no leían una página de izquierda a derecha, de arriba abajo. Por el contrario, ojeaban superficialmente, buscando información de interés. El efecto más importante de utilizar la red es que se ha dejado en desuso nuestro procesamiento lineal de pensamiento ( $\sin$ distracciones y centrado), procesamiento fomentado por el medio impreso. El nuevo tipo de procesamiento requiere información rápida, corta y desintegrada.

\section{OBjetivos}

\section{Objetivo general}

Analizar la relación entre los hábitos de consumo de las plataformas en línea Facebook y YouTube, la conciencia metacognitiva, la metacognición relacionada con la lectura y las estrategias de estudio y aprendizaje en estudiantes universitarios de primeros ciclos.

\section{Objetivos específicos}

1) Caracterizar los hábitos de consumo de las plataformas Facebook y YouTube en estudiantes universitarios de primeros ciclos. 
2) Establecer la conciencia metacognitiva en estudiantes universitarios de primeros ciclos.

3) Identificar las estrategias metacognitivas en la lectura en estudiantes universitarios de primeros ciclos.

4) Establecer las estrategias de aprendizaje y estudio en estudiantes universitarios de primeros ciclos.

\section{HIPÓTESIS}

H1: Los estudiantes universitarios utilizan con mayor frecuencia la plataforma en línea Facebook.

$\mathrm{H} 2$ : Los estudiantes universitarios presentan un bajo nivel de desarrollo de la conciencia metacognitiva.

H3: Los estudiantes universitarios presentan un bajo nivel de desarrollo de las estrategias metacognitivas en la lectura.

H4: Los estudiantes universitarios presentan un nivel de desarrollo diferenciado en el desarrollo de las estrategias de aprendizaje y estudio.

H5: Existe una relación negativa entre los hábitos de consumo de plataformas en línea y la conciencia metacognitiva.

H6: Existe una relación negativa entre los hábitos de consumo de plataformas en línea y las estrategias metacognitivas en la lectura.

H7: Existe una relación negativa entre los hábitos de consumo de plataformas en línea y la aplicación de estrategias de aprendizaje y estudio.

\section{MÉTODO}

En la medida en que se propone establecer la relación entre las variables estudiadas en un determinado contexto, el estudio corresponde a una investigación de nivel descriptivo y tipo correlacional (Hernández, Fernández \& Baptista, 2010).

\section{Participantes}

Para el desarrollo del estudio se estableció como población objetiva los alumnos universitarios de los primeros ciclos de las diferentes carreras que se brindan en universidades estatales y particulares. Para ello se aplicó un muestreo de tipo no probabilístico intencionado (Lohr, 2000). Se eligieron como criterios de inclusión que los alumnos cursen el primero o segundo ciclo y que sean regulares (que llevaran más de 12 créditos). Para obtener la muestra se eligieron cuatro universidades particulares y una estatal, por ser las que tenían la mayor variedad de carreras. Se realizaron las coordinaciones necesarias, se eligieron las aulas de los primeros ciclos y se evaluaron los alumnos para formar la muestra.

En total se evaluaron 463 casos, distribuidos de la siguiente forma: el $64,6 \%$ estuvo conformado por participantes mujeres y el $35,4 \%$ por varones. Las edades fluctúan entre los 16 y los 23 años, siendo la mayor concentración entre 17 y 18. Con relación a la universidad de procedencia, 
Tabla 1

Composición de la muestra

\begin{tabular}{llcc}
\hline & Valores & Frecuencia & Porcentaje \\
\hline Sexo & Masculino & 164 & 35,4 \\
& Femenino & 299 & 64,6 \\
\hline Universidad & Particular 1 & 82 & 17,7 \\
& Particular 2 & 89 & 19,2 \\
& Particular 3 & 125 & 27,0 \\
& Particular 4 & 17 & 3,7 \\
& Estatal 1 & 150 & 32,4 \\
\hline Ciclo & Primero & 107 & 23,1 \\
& Segundo & 356 & 76,9 \\
\hline Carrera que estudian & Ciencias de la salud & 104 & 22,5 \\
& Ciencias de la comunicación y arte & 90 & 19,4 \\
& Ciencias administrativas y contables & 86 & 18,6 \\
& Ingenierías & 183 & 39,5 \\
\hline & Total & 463 & 100 \\
\hline
\end{tabular}

la mayor proporción correspondió a la estatal $1(32,4 \%)$ seguida por la particular $3(27,0 \%)$, la particular $2(19,2 \%)$, la particular $1(17,7 \%)$ y la particular $4(3,7 \%)$. La mayoría de participantes cursaban el segundo ciclo (76,9\%), seguido por el primer ciclo $(23,1 \%)$ (véase la tabla 1).

\section{Instrumentos}

Los instrumentos de investigación corresponden a:

- Escaladeconcienciametacognitiva.Mide el desarrollo de la conciencia metacognitiva de los alumnos uni- versitarios, para ello se evaluaron los componentes más relevantes reportados por la bibliografía (Flavell, 1979; Mayor, Suengas \& González, 1993). El instrumento, construido para la presente investigación, estuvo conformado por 32 enunciados acerca de las formas de comportarse en diferentes situaciones académicas, los cuales deberían de calificarse de acuerdo con una escala tipo Likert de 5 puntos. La escala tuvo las siguientes áreas:

1) Conocimientos sobre la cogni_ ción. Está conformada por 12 ítems y mide 3 tipos de conocimientos: 
a) El conocimiento declarativo: se refiere al conocimiento de los hechos que el alumno necesita saber antes de procesar y evaluar un determinado tema; es el conocimiento de las propias habilidades, de un tema y de sus recursos intelectuales como estudiante.

b) El conocimiento procedimental: mide la aplicación del conocimiento para completar un proceso de aprendizaje; requiere que los estudiantes conozcan el proceso de aprendizaje, así como cuándo dicho proceso se puede aplicar a diferentes situaciones.

c) El conocimiento condicional: mide la habilidad para identificar las circunstancias concretas que se deben transferir para generar un aprendizaje; es el conocimiento sobre cuándo $\mathrm{y}$ por qué utilizar el aprendizaje y sus procedimientos.

2) Regulación. Mide la forma cómo los estudiantes regulan la cognición. Está constituida por 20 ítems e incluye los siguientes aspectos:

a) Planificación: mide el establecimiento de metas antes de la situación de aprendizaje.

b) Información de las estrategias de gestión: mide las habilida- des y secuencias de la estrategia utilizada para procesar la información de manera más eficiente. Por ejemplo, organizar, elaborar o resumir la información.

c) Seguimiento y monitoreo de la comprensión: mide la evaluación del propio aprendizaje, del aprendizaje que está ocurriendo o el uso de estrategias (cómo se aprende).

d) Depuración de las estrategias: mide las estrategias utilizadas para corregir la comprensión y el rendimiento erróneo.

e) Evaluación: mide el análisis del rendimiento y la eficacia de la estrategia después de un episodio de aprendizaje.

El análisis psicométrico incluido en la tabla 2 permite notar que tanto la escala de conocimiento, la escala de regulación y la escala total obtienen correlaciones ítems test corregidas (ritc) superiores al valor de 0.20 (Kline, 1986), lo que aporta evidencias para la validez de contenido (Anastasi \& Urbina, 1998; Santisteban, 2009). Además, los coeficientes alfa de Cronbach son superiores a 0.80 y adicionalmente la escala total presenta un valor de 0.92 , hallazgos que permiten concluir que la escala de conciencia metacognitiva presenta confiabilidad por consistencia interna. 
Tabla 2

Resumen de la evidencia de la validez de contenido y confiabilidad de la escala de conciencia metacognitiva

\begin{tabular}{lcccc}
\hline $\begin{array}{c}\text { Conciencia } \\
\text { metacognitiva }\end{array}$ & N $^{\circ}$ ítems & $\begin{array}{c}\text { ritc } \\
\text { mínimo }\end{array}$ & $\begin{array}{c}\text { ritc } \\
\text { máximo }\end{array}$ & $\begin{array}{c}\text { Alfa de } \\
\text { Cronbach }\end{array}$ \\
\hline C. M. Conocimiento & 12 & 0.21 & 0.50 & 0.82 \\
C. M. Regulación & 20 & 0.20 & 0.55 & 0.87 \\
C. M. Total & 32 & 0.25 & 0.70 & 0.92 \\
\hline
\end{tabular}

$\mathrm{N}=463$

- Escala de estrategias metacognitivas en la lectura.- Mide la habilidad para aplicar las estrategias metacognitivas durante el proceso de lectura de los estudiantes universitarios, a fin de lograr una mejor comprensión del texto.

La escala fue construida para la presente investigación tomando en cuenta las estrategias para la lectura propuestas por Mokhtari y Reichard (2002). El instrumento estuvo conformado por 18 enunciados acerca de formas de comportarse durante el proceso de la lectura que eran calificados de acuerdo con una escala tipo Likert de 5 puntos de calificación

La estructura del instrumento incluyó la evaluación de las siguientes estrategias de lectura:

a) Estrategia global: mide el uso de las estrategias orientadas hacia el análisis general del texto; está conformado por 6 ítems. b) Solución de problemas en la lectura: mide las estrategias orientadas a la búsqueda de solución de problemas que se presentan cuando el texto es difícil de ser leído; está conformado por 6 ítems.

c) Estrategias de apoyo a la lectura: mide las estrategias en el uso de materiales de referencia, como tomar notas y la aplicación de otros procedimientos prácticos; está constituido por 6 ítems.

El análisis psicométrico, presentado en la tabla 3 , indica que la estrategia global, la estrategia de solución de problemas y la estrategia de apoyo a la lectura presentan correlaciones ítems test corregidas (ritc) superiores al valor de 0.20 (Kline, 1986), lo que aporta evidencias para la validez de contenido (Anastasi \& Urbina, 1998; Santisteban, 2009). 
Tabla 3

Resumen de las evidencias de la validez de contenido y confiabilidad de la escala de estrategias metacognitivas en la lectura

\begin{tabular}{lcccc}
\hline Estrategias metacognitivas en la lectura & $\begin{array}{c}\mathbf{N}^{\circ} \\
\text { ítems }\end{array}$ & $\begin{array}{c}\text { ritc } \\
\text { mínimo }\end{array}$ & $\begin{array}{c}\text { ritc } \\
\text { máximo }\end{array}$ & $\begin{array}{c}\text { Alfa de } \\
\text { Cronbach }\end{array}$ \\
\hline Estrategia global & 6 & 0.21 & 0.68 & 0.76 \\
Estrategia de solución de problemas & 6 & 0.20 & 0.65 & 0.73 \\
Estrategia de apoyo a la lectura & 6 & 0.22 & 0.64 & 0.71 \\
Estrategia metacognitivas en la lectura total & 18 & 0.25 & 0.70 & 0.87 \\
\hline
\end{tabular}

$N=463$

Adicionalmente, se encuentra que las escalas de las estrategias evaluadas alcanzaron coeficientes alfa de Cronbach superiores a 0.70 . Además, se encuentra que la escala total obtiene un valor de 0.87 , por lo que se puede concluir que la escala de estrategias metacognitivas en la lectura presenta confiabilidad por consistencia interna.

- Inventario de estrategia de aprendizaje y estudio (IEAE) forma corta.Mide las estrategias utilizadas para el estudio y el aprendizaje que utilizan los estudiantes universitarios. A partir del estudio de adaptación psicométrica realizado en la ciudad de Lima (Escurra, 2006), se procedió a desarrollar una forma corta del instrumento a fin de ser aplicado en el presente estudio. Para ello se procedió a seleccionar los 4 mejores ítems de cada uno de aspectos evaluados:

a) Procesamiento de la información: mide la forma como el estudian- te utiliza su imaginación, elaboraciones verbales, estrategias de organización, las habilidades de razonamiento y las habilidades para aprender las estrategias para ayudar al aprendizaje.

b) Detección de ideas principales: mide la habilidad para identificar, durante el estudio, la información relevante de aquella que no lo es.

c) Estrategia para el examen: mide el uso por parte de los estudiantes de la forma como se preparan para dar una prueba y las estrategias que utilizan para responder.

d) Ansiedad: mide el grado de preocupación de los estudiantes por la universidad y su actuación académica.

e) Actitud: mide las actitudes e intereses de los estudiantes por la universidad y el éxito académico.

f) Motivación: mide la disposición al esfuerzo necesario para lograr o superar los retos académicos. 
g) Concentración: mide la habilidad del estudiante para dirigir y mantener su atención en el desarrollo de tareas académicas.

h) Autoevaluación: mide el uso del repaso y la comprensión para determinar el nivel de entendimiento de la información o el tema que debe ser aprendido.

i) Ayudas para el estudio: mide el uso de técnicas de apoyo, materiales o recursos como ayudas para aprender o recordar la nueva información.

j) Administración del tiempo: mide la forma en que los estudiantes se organizan para distribuir el tiempo asignado para las tareas académicas.
En lo que respecta al análisis psicométrico (véase la tabla 4), se encuentra que todas las áreas evaluadas obtienen correlaciones ítems test corregidas (ritc) superiores al valor de 0.20 (Kline, 1986), lo que aporta evidencias para la validez de contenido (Anastasi \& Urbina, 1998; Santisteban, 2009). Además, se encuentra que los coeficientes alfa de Cronbach se dan en dos niveles. En primer lugar se encuentran los valores adecuados que corresponden a los iguales o mayores de 0.70 , que incluyen las subescalas de actitud (0.76), concentración (0.74), motivación $(0.73)$, procesamiento de información (0.73), administración del tiempo (0.71), estrategias para el examen (0.71), ansiedad (0.70),

Tabla 4

Resumen de las evidencias de la validez de contenido y confiabilidad del inventario de estrategias de aprendizaje y estudio (IEAE)

\begin{tabular}{lcccc}
\hline \multicolumn{1}{c}{ Estrategia de lectura } & $\begin{array}{c}\mathbf{N}^{\circ} \\
\text { ítems }\end{array}$ & $\begin{array}{c}\text { ritc } \\
\text { mínimo }\end{array}$ & $\begin{array}{c}\text { ritc } \\
\text { máximo }\end{array}$ & $\begin{array}{c}\text { Alfa } \\
\text { de Cronbach }\end{array}$ \\
\hline Actitud & 4 & 0.20 & 0.59 & 0.76 \\
Motivación & 4 & 0.21 & 0.60 & 0.73 \\
Administración del tiempo & 4 & 0.22 & 0.70 & 0.71 \\
Ansiedad & 4 & 0.20 & 0.64 & 0.70 \\
Concentración & 4 & 0.21 & 0.68 & 0.74 \\
Procesamiento de información & 4 & 0.22 & 0.67 & 0.73 \\
Detección de ideas principales & 4 & 0.23 & 0.59 & 0.67 \\
Ayudas para el estudio & 4 & 0.20 & 0.62 & 0.69 \\
Autoevaluación & 4 & 0.22 & 0.70 & 0.70 \\
Estrategia para el examen & 4 & 0.20 & 0.69 & 0.71 \\
\hline
\end{tabular}

$N=463$ 
autoevaluación (0.70). En segundo lugar, se observan los coeficientes entre 0.60 y 0.69 , como son los casos de las subescalas de ayudas para el estudio (0.69) y detección de ideas principales $(0.67)$. Los hallazgos alcanzados permiten concluir que el inventario de estrategias de aprendizaje y estudio (IEAE) presenta confiabilidad por consistencia interna.

- Escala de hábitos de consumo de plataformas en línea.- A fin de cuantificar cómo eran los hábitos de consumo de plataformas en línea, se procedió a construir el instrumento respectivo, para ello se tomaron en cuenta las plataformas Facebook y YouTube, y se incluyeron los siguientes aspectos: a) Frecuencia y antigüedad de uso: indica la antigüedad en el uso de la plataforma en línea y la frecuencia de su uso diario; está compuesta por 4 ítems.

b) Objetivos de uso: señala el uso que le da el usuario a las diferentes plataformas en línea; está compuesta por 15 ítems.

c) Enfoque centrado en el producto en línea: mide el grado en que se usan simultáneamente la plataforma en línea y otros programas. Así como el tiempo sin interrupciones en que se usa la plataforma en línea; está compuesta por 4 ítems.

El análisis psicométrico presentado en la tabla 5, permite apreciar

Tabla 5

Análisis de las evidencias de la validez de contenido y confiabilidad de la escala de hábitos de consumo de plataformas en línea

\begin{tabular}{cccccccc}
\hline Preguntas & Media & D. E. & ritc & Preguntas & Media & D. E. & ritc \\
\hline 1 & 2.77 & 1.15 & 0.29 & 13 & 0.60 & 0.49 & 0.35 \\
2 & 4.09 & 1.18 & 0.22 & 14 & 0.27 & 0.44 & 0.35 \\
3 & 2.67 & 1.32 & 0.34 & 15 & 0.52 & 0.50 & 0.33 \\
4 & 2.14 & 1.18 & 0.22 & 16 & 0.27 & 0.44 & 0.24 \\
5 & 0.71 & 0.45 & 0.29 & 17 & 0.49 & 0.50 & 0.21 \\
6 & 0.23 & 0.42 & 0.21 & 18 & 0.69 & 0.46 & 0.27 \\
7 & 0.23 & 0.42 & 0.26 & 19 & 0.22 & 0.42 & 0.23 \\
8 & 0.58 & 0.49 & 0.31 & 20 & 0.84 & 0.37 & 0.30 \\
9 & 0.53 & 0.50 & 0.20 & 21 & 3.04 & 1.39 & 0.29 \\
10 & 0.75 & 0.44 & 0.37 & 22 & 0.56 & 0.50 & 0.25 \\
11 & 0.66 & 0.48 & 0.27 & 23 & 2.82 & 1.49 & 0.24 \\
12 & 0.43 & 0.49 & 0.40 & & & & \\
\hline
\end{tabular}

Alfa de Cronbach $=0.76$

$N=463$ 
que todas las preguntas alcanzan correlaciones ítems test corregidas (ritc) superiores al valor de 0.20 (Kline, 1986), hallazgo que aporta evidencias para la validez de contenido. También se alcanza un coeficiente alfa de Cronbach de 0.76 , lo cual permite concluir que la escala de hábitos de consumo de plataformas en línea presenta confiabilidad por consistencia interna.

\section{Procedimientos}

Una vez aplicados los instrumentos se procedió a revisar cada una de las aplicaciones a fin de establecer si había respuestas omitidas. Se estableció que las encuestas con más de 10 respuestas en blanco deberían ser eliminadas. Una vez depurados los datos, estos fueron digitados en el programa SPSS 21 y se procedió a realizar los análisis en los siguientes niveles:

a) En el nivel psicométrico se analizó la calidad de los instrumentos procesados. Para ello, en cada escala se estudió la validez de contenidos y la confiabilidad por consistencia interna. Se calcularon las correlaciones ítems test corregidas y el coeficiente alpha de Cronbach.

b) El análisis descriptivo fue ejecutado con la finalidad de identificar las características de la muestra, las preguntas de la encuesta y las propiedades numéricas de las variables cuantitativas. Se utilizó el análisis de frecuencias y porcentajes para las variables cualitativas. Para las variables cuantitativas se utilizó la media, la desviación estándar y el análisis de normalidad a través de la prueba de Kolmogorov-Smirnov.

c) Análisis inferencial del contraste de hipótesis: para el contraste de la hipótesis 1, hipótesis 2, hipótesis $3 \mathrm{e}$ hipótesis 4 las variables numéricas fueron clasificadas en variables cualitativas según el nivel de desarrollo alcanzado por los estudiantes (alto, medio, bajo). Por consiguiente, se aplicaron estadísticas no paramétricas, como la del Chi-cuadrado de una muestra. En el caso de las hipótesis 5, 6 y 7, dado que las variables se analizaron de forma cuantitativa, en primer lugar se realizó un análisis exploratorio de datos y al observar las formas de la distribución se optó por utilizar la técnica de los grupos extremos aplicándose las correlaciones de Spearman (Siegel \& Castellan, 1995).

\section{Resultados}

Caracterización de las plataformas en línea

A continuación se procederá a presentar los resultados de la caracterización de cada una de las plataformas en línea analizadas.

La plataforma Facebook obtiene los mayores porcentajes de uso (76\%). En 
segundo lugar, encontramos que el uso conjunto de YouTube y Facebook presenta un $12,5 \%$. Por último, el uso exclusivo de YouTube solo lo prefieren un $11,5 \%$.

\section{Caracterización del uso de Facebook}

Con relación al análisis de la plataforma Facebook se encuentra que la mayor proporción de casos se concentra entre los que la utilizan desde hace un año $(29,2 \%)$ y los que la usan desde hace dos años (30,5\%).

Continuando con la plataforma en línea Facebook, la mayor concentración de uso diario está entre los que indican que la usan menos de una hora (20,7 \%), los que usan de 1 a 2 horas $(32,4 \%)$ y de 2 a 3 horas $(20,5 \%)$. No obstante, es necesario notar que el uso intensivo, que incluye de 3 horas a más, supone el $26,4 \%$ de la muestra.

En relación con la aplicación que se hace de la plataforma Facebook el mayor uso corresponde a la categoría «Mantenerse en contacto con su círculo social de amigos y familiares» (74,7 \%), seguido por «Intercambio de información» $(71,1 \%)$ y por «Comunicarse con su círculo social de amigos y familiares» $(65,9 \%)$. También es relevante indicar que las elecciones menos frecuentes corresponden a «Dar y recibir apoyo social» $(22,7 \%)$, seguido por «Conocer nuevas personas» $(23,1 \%)$ y «Estar al tanto de lo que ocurre en su círculo social» $(26,6 \%)$.
Los alumnos encuestados indicaron que cuando usan el ordenador normalmente mantienen abierta la plataforma Facebook en el 84,2 \% de los casos.

Respecto a la cantidad de ventanas que se tiene abierta además del Facebook, el mayor porcentaje de alumnos indicó tener tres ventanas más el $28,3 \%$; cuatro ventanas más el 19,9\%, y dos ventanas más el 19,7\%. Es importante indicar que solo el 5,2 \% declaró tener abierta una ventana más.

El análisis del tiempo promedio en que se utiliza el Facebook sin ver otro programa o realizar otra tarea indica que en el $23,1 \%$ se da en intervalos de 10 a 15 minutos, en el 22,9\% en intervalos de 5 a 10 minutos, y en el $22 \%$ se da en intervalos de más de 20 minutos.

El análisis de la evaluación de la manera en que están presentados los elementos del Facebook nos demuestra que el 63,5\% de estudiantes lo percibe como una red social "Atractiva» o «Muy atractiva», mientras que solo el $7,8 \%$ lo considera como «Nada atractiva» 0 «Poco atractiva».

Respecto a la facilidad de manejo de la red social Facebook, más de la mitad de la muestra $(54,5 \%)$ indica es «Alta» o «Muy alta»; en tanto que el 8,5\% declara que es «Baja»o «Muy baja».

También se observa que el 43,2\% («Frecuentemente»y «Siempre») declara que revisa el Facebook sin seguir un 
orden en particular, centrándose en lo que llame su atención. Por el contrario, aquellos que sí mantienen un orden en particular conforman un 18,2\% («Nunca», «Casi nunca»). Por otro lado, los resultados evidencian que el $70 \%$ de la muestra examina de uno a tres elementos a la vez; el 11,4 \% examina de cuatro a más elementos.

\section{Características del uso de YouTube}

Con relación al análisis de la plataforma YouTube, se encuentra que la mayor proporción de casos se concentra entre los que la utilizan desde hace tres o más años. Ellos forman el 74,1 \%.

El análisis del uso diario de YouTube demuestra que el 69,5\% la utiliza de menos de una hora a dos horas, mientras que el $14,4 \%$ la utiliza de 3 a más horas por día.

Respecto a YouTube, la mayor parte de la muestra la utiliza como entretenimiento $(68,7 \%)$, seguida por «Realizar tareas académicas» $(48,6 \%)$. Por otro lado, solo el 22,2 \% la emplea para estar al tanto de lo que ocurre en el mundo.

La mayoría de los participantes $(55,7$ $\%$ ) indica que cuando utiliza la computadora mantiene abierto YouTube. También se encuentra que el $44,3 \%$ declara que no tiene abierta una ventana además de YouTube. También se puede apreciar que el $31,5 \%$ sostiene que tiene abiertas de dos a tres ventanas más.
Por otra parte, el 47,5\% de los encuestados indica que en promedio utiliza YouTube sin ver otro programa o realizar otra tarea entre menos de $5 \mathrm{y}$ 10 minutos. Es necesario destacar que el $21,6 \%$ utiliza YouTube sin ver otro programa más de 20 minutos.

Con respecto a la percepción de la manera en que están presentados los elementos de YouTube, el 45,1 \% indica que la forma de presentación es «Atractiva» o «Muy atractiva», en tanto que el $12,6 \%$ sostiene que es «Nada» o «Poco atractiva».

En cuanto a la evaluación de la facilidad de manejo de YouTube, el $53 \%$ declara que es «Alta» o «Muy alta». En contraste con lo anterior, solo el $11 \%$ plantea que la facilidad de manejo es «Muy baja» o «Baja».

Con relación a la forma de revisar YouTube sin seguir un orden en particular, centrándose en lo que llame su atención, el 48,2 \% indica que «Frecuentemente» o «Siempre» lo hace, mientras que el 19,9\% indica que siguen un orden en particular, no centrándose en los elementos que llaman su atención.

En lo concerniente a la cantidad de elementos que se revisan simultáneamente en YouTube, el 77,4 \% indica que examina de uno a tres elementos a la vez, en tanto que solo el 7,8 \% examina de cuatro a más elementos a la vez. 


\section{ANÁLISIS DESCRIPTIVO}

El análisis descriptivo de las variables numéricas (tabla 6), indica que solo las siguientes variables presentaron una adecuada aproximación a la distribución normal: la conciencia metacognitiva total $(\mathrm{KS}-\mathrm{Z}=1.06, \mathrm{p}=.210)$, la regulación de la conciencia metacognitiva $(\mathrm{KS}-\mathrm{Z}=0.89, \mathrm{p}=.411)$, las estrate- gias metacognitivas en la lectura total $(\mathrm{KS}-\mathrm{Z}=0.85, \mathrm{p}=.464)$ y los hábitos de consumo de plataformas en línea $(\mathrm{KS}-\mathrm{Z}=1.20, \mathrm{p}=.057)$. En tanto que las restantes estrategias metacognitivas de lectura y las estrategias de aprendizaje y estudio alcanzaron resultados que indicaron no aproximarse adecuadamente a la distribución normal.

Tabla 6

Análisis descriptivo de las variables estudiadas

\begin{tabular}{lcccc}
\hline & Media & D. E. & KS-Z & P \\
\hline Conciencia metacognitiva & & & & \\
Total & 2.27 & 0.47 & 1.06 & .210 \\
Conocimientos & 2.20 & 0.51 & 2.11 & .000 \\
Regulación & 2.30 & 0.49 & 0.89 & .411 \\
\hline Estrategias metacognitivas en la lectura & & & & \\
Total & 2.20 & 0.54 & 0.85 & .464 \\
Global & 2.28 & 0.61 & 1.91 & .001 \\
Solución de problemas & 2.08 & 0.57 & 1.99 & .001 \\
Apoyo a la lectura & 2.25 & 0.67 & 1.69 & .006 \\
\hline Estrategias de aprendizaje y estudio & & & & \\
Actitud & 3.21 & 0.80 & 1.69 & .006 \\
Motivación & 2.20 & 0.63 & 1.85 & .002 \\
Administración del tiempo & 2.84 & 0.69 & 2.06 & .000 \\
Ansiedad & 2.79 & 0.73 & 1.79 & .003 \\
Concentración & 3.11 & 0.73 & 2.19 & .000 \\
Procesamiento de información & 2.23 & 0.64 & 1.74 & .005 \\
Detección de ideas principales & 2.72 & 0.54 & 2.56 & .000 \\
Ayudas para el estudio & 2.23 & 0.68 & 2.49 & .000 \\
Autoevaluación & 2.58 & 0.71 & 2.13 & .000 \\
Estrategia para el examen & 3.08 & 0.76 & 2.09 & .000 \\
\hline Hábitos de consumo & & & & \\
de plataformas en línea & & 4.67 & 1.20 & .057 \\
\hline & & & & \\
\hline
\end{tabular}

$N=463$ 
ANÁLISIS INFERENCIAL DEL CONTRASTE DE HIPÓTESIS

Los resultados de la hipótesis 1, incluidos en la tabla 7, permiten ver que hay diferencias estadísticas significativas $\left(X^{2}(2)=379.83, \mathrm{P}=.001\right)$, notándose que predominan los alumnos que utilizan principalmente la plataforma en línea Facebook, por lo que la hipótesis es válida.
El análisis del contraste de la hipótesis 2 (tabla 8), permite ver que hay diferencias estadísticas significativas en el total de la conciencia metacognitiva $\left(X^{2}(2)=332.91, \mathrm{P}=.001\right)$, el área de conocimientos $\left(X^{2}(2)=417.96 \mathrm{Gl} .=2\right.$, $\mathrm{P}=.001)$ y el área de regulación $\left(X^{2}(2)\right.$ $=281.99, \mathrm{P}=.001)$. En los tres casos se puede notar que predominan los alumnos con bajo nivel de desarrollo, por lo que la hipótesis es válida.

Tabla 7

Análisis del uso de plataformas en línea

\begin{tabular}{lccc}
\hline Plataforma en línea & N observado & N esperado & Residual \\
\hline Facebook & 352 & 154,3 & 197,7 \\
YouTube & 53 & 154,3 & $-101,3$ \\
Facebook y YouTube & 58 & 154,3 & $-196,3$ \\
\hline Total & 463 & & \\
\hline
\end{tabular}

Chi-cuadrado $=379.83 \quad$ G. L. $=2 p=.001$

Tabla 8

Análisis del nivel de conciencia metacognitiva

\begin{tabular}{lccccccc}
\hline \multirow{2}{*}{$\begin{array}{c}\text { Conciencia } \\
\text { metacognitiva }\end{array}$} & \multicolumn{3}{c}{ N observado } & \multicolumn{2}{c}{ N esperado } & $\begin{array}{c}\text { Chi- } \\
\text { cuadrado }\end{array}$ & P \\
\cline { 2 - 6 } & Nivel bajo & Nivel medio & Nivel alto & & & \\
\hline Total & 325 & 131 & 7 & 154.3 & 332.91 & .001 \\
Conocimientos & 354 & 103 & 6 & 154.3 & 417.96 & .001 \\
Regulación & 303 & 152 & 8 & 154.3 & 281.99 & .001 \\
\hline
\end{tabular}

G. L. $=2$ 
Tabla 9

Análisis del nivel de estrategias metacognitivas en la lectura

\begin{tabular}{lcccccc}
\hline $\begin{array}{l}\text { Estrategias } \\
\text { metacognitivas } \\
\text { en la lectura }\end{array}$ & $\begin{array}{l}\text { Nivel } \\
\text { bajo }\end{array}$ & $\begin{array}{c}\text { Nivel } \\
\text { medio }\end{array}$ & $\begin{array}{c}\text { Nivel } \\
\text { alto }\end{array}$ & $\begin{array}{c}\text { N } \\
\text { esperado }\end{array}$ & $\begin{array}{c}\text { Chi- } \\
\text { cuadrado }\end{array}$ & P \\
\cline { 2 - 6 } Total & 327 & 129 & 7 & 154.3 & 337.99 & .001 \\
Global & 289 & 159 & 15 & 154.3 & 242.44 & .001 \\
Solución de problemas & 338 & 116 & 9 & 154.3 & 361.96 & .001 \\
Apoyo a la lectura & 292 & 52 & 19 & 154.3 & 241.51 & .001 \\
\hline
\end{tabular}

G. L. $=2$

En el análisis del contraste de la hipótesis 3 (véase la tabla 9), con relación a las estrategias metacognitivas en la lectura, se encuentra que existen diferencias estadísticas significativas en el total de estrategias metacognitivas en la lectura $\left(X^{2}(2)=337.99, \mathrm{P}=.001\right)$, así como en las estrategias específicas de lectura de forma global $\left(X^{2}(2)=242.44\right.$, $\mathrm{P}=.001)$, en la estrategia de solución de problemas $\left(X^{2}(2)=361.96, \mathrm{P}=.001\right)$ y en la estrategia de apoyo a la lectura $\left(X^{2}(2)=241.51, \mathrm{P}=.001\right)$, notándose que en todos los casos predominan los alumnos con nivel bajo de desarrollo de las estrategias metacognitivas en la lectura, por lo que la hipótesis es válida.

En el análisis de los resultados del contraste de las áreas de la escala de estrategias de aprendizaje y estudio (véase la tabla 10), se encuentra que en todos los casos existen diferencias significativas $(\mathrm{P}=.001)$.

Se debe resaltar que existen diferencias en cuanto al nivel de desarrollo que predomina en los alumnos. Así, se encuentra que predomina un nivel alto en la estrategia de actitud hacia el estudio. Por otro lado, apreciamos un nivel medio en las estrategias de administración del tiempo, ansiedad, concentración, detección de ideas principales, autoevaluación y estrategias para el examen. En tanto que los niveles bajos predominan en las estrategias de motivación, procesamiento de información y ayudas para el estudio.

Estos hallazgos permiten concluir que la hipótesis es válida. 
Tabla 10

Análisis del nivel de estrategias de aprendizaje y estudio

\begin{tabular}{|c|c|c|c|c|c|c|}
\hline \multirow{2}{*}{$\begin{array}{l}\text { Estrategias de } \\
\text { aprendizaje y estudio }\end{array}$} & \multicolumn{3}{|c|}{ N observado } & \multirow{2}{*}{$\begin{array}{c}\mathrm{N} \\
\text { esperado }\end{array}$} & \multirow{2}{*}{$\begin{array}{l}\text { Chi- } \\
\text { cuadrado }\end{array}$} & \multirow{2}{*}{$\mathbf{P}$} \\
\hline & $\begin{array}{l}\text { Nivel } \\
\text { bajo }\end{array}$ & $\begin{array}{l}\text { Nivel } \\
\text { medio }\end{array}$ & $\begin{array}{l}\text { Nivel } \\
\text { alto }\end{array}$ & & & \\
\hline Actitud & 71 & 192 & 200 & 154.3 & 67.70 & .001 \\
\hline Motivación & 291 & 159 & 13 & 154.3 & 250.92 & .001 \\
\hline $\begin{array}{l}\text { Administración del } \\
\text { tiempo }\end{array}$ & 114 & 240 & 109 & 154.3 & 71.41 & .001 \\
\hline Ansiedad & 129 & 230 & 104 & 154.3 & 55.67 & .001 \\
\hline Concentración & 81 & 217 & 165 & 154.3 & 61.03 & .001 \\
\hline $\begin{array}{l}\text { Procesamiento de } \\
\text { información }\end{array}$ & 293 & 145 & 25 & 154.3 & 233.54 & .001 \\
\hline $\begin{array}{l}\text { Detección de ideas } \\
\text { principales }\end{array}$ & 108 & 305 & 40 & 154.3 & 265.87 & .001 \\
\hline Ayudas para el estudio & 262 & 179 & 22 & 154.3 & 192.52 & .001 \\
\hline Autoevaluación & 182 & 222 & 59 & 154.3 & 93.52 & .001 \\
\hline $\begin{array}{l}\text { Estrategia para el } \\
\text { examen }\end{array}$ & 76 & 223 & 164 & 154.3 & 70.92 & .001 \\
\hline
\end{tabular}

G. L. $=2$

En cuanto al contraste de la hipótesis específica $\mathrm{H}-5$, la tabla 11 permite apreciar que existen correlaciones estadísticas significativas, negativas y moderadas entre los hábitos de consumo de las plataformas en línea y el total de la conciencia metacognitiva $\left(r_{s}=-0.39\right.$, $\mathrm{p}<.001)$, el área de regulación $\left(\mathrm{r}_{\mathrm{s}}=-\right.$ $0.40, \mathrm{p}<.001)$. Además, se encontró que el uso de las plataformas en línea se correlacionan de forma significativa, negativa y baja con los conocimientos $\left(r_{s}=-0.32, p<.001\right)$. De acuerdo con la clasificación propuesta por Cohen (1988), todas las correlaciones presentan un tamaño del efecto pequeño, por lo que se puede concluir que la hipótesis es válida. 
Tabla 11

Correlaciones entre los hábitos de consumo de plataformas en línea y la conciencia metacognitiva

\begin{tabular}{lc}
\hline $\begin{array}{c}\text { Conciencia } \\
\text { metacognitiva }\end{array}$ & $\begin{array}{c}\text { Hábitos de consumo de } \\
\text { plataformas en línea } \\
\mathbf{r}_{\mathrm{s}}\end{array}$ \\
\hline Conocimientos & $-0.32^{* * *}$ \\
Regulación & $-0.40^{* * *}$ \\
Total & $-0.39^{* *}$ \\
\hline
\end{tabular}

$\mathrm{N}=240^{* *} \mathrm{p}<.01{ }^{* * *} \mathrm{p}<.001$

Tabla 12

Correlaciones entre los hábitos de consumo de plataformas en línea y las estrategias metacognitivas en la lectura

\begin{tabular}{lc}
\hline Variables & $\begin{array}{c}\text { Hábitos de consumo de } \\
\text { plataformas en línea } \\
r_{s}\end{array}$ \\
\hline Global & $-0.30^{* * *}$ \\
Solución de problemas & $-0.19^{* *}$ \\
Apoyo a la lectura & $-0.26^{* * *}$ \\
Total & $-0.29^{* * *}$ \\
\hline
\end{tabular}

$\mathrm{N}=240 \quad{ }^{* *} \mathrm{P}<.01{ }^{* * *} \mathrm{p}<.01$

El análisis de la hipótesis 6 (véase la tabla 12) indica que hay correlaciones estadísticas significativas y negativas pero bajas entre los hábitos de consumo de plataformas en línea y el total de estrategias metacognitivas en la lectura $\left(r_{\mathrm{s}}=-0.29, \mathrm{p}<.001\right)$, la estrategia global de lectura $\left(r_{s}=-0.30, p<.001\right)$, la estrategia de apoyo a la lectura $\left(r_{s}=-0.26\right.$, $\mathrm{p}<.05)$ y la estrategia de solución de problemas $\left(\mathrm{r}_{\mathrm{s}}=-0.19, \mathrm{p}<.001\right)$, por los hallazgos alcanzados se concluye que la hipótesis no es válida. 
Respecto al análisis de la hipótesis 7 (tabla 13), se puede notar que hay correlaciones estadísticas significativas, positivas y bajas entre los hábitos de consumo de plataformas en línea y la motivación $\left(\mathrm{r}_{\mathrm{s}}=0.21, \mathrm{p}<.01\right)$, concentración $\left(\mathrm{r}_{\mathrm{s}}=0.21, \mathrm{p}<.01\right)$, ansiedad $\left(r_{\mathrm{s}}=0.17, \mathrm{p}<.01\right)$, y la estrategia para el examen $\left(r_{s}=0.17, p<.01\right)$.

También se encontraron correlaciones estadísticas significativas, negativas y bajas entre los hábitos de consumo de plataformas en línea y la autoevaluación $\left(\mathrm{r}_{\mathrm{s}}=-0.29, \mathrm{p}<.001\right)$, ayudas para el estudio $\left(r_{s}=-0.28, p<.001\right)$ y el procesamiento de información $\left(\mathrm{r}_{\mathrm{s}}=\right.$ $0.22, \mathrm{p}<.01)$. Debido a los hallazgos se concluye que la hipótesis no es válida.
ANÁLISIS Y DISCUSIÓN

Los instrumentos de investigación incluidos en el estudio han demostrado cumplir con los criterios psicométricos básicos, como son presentar evidencias de validez y confiabilidad (Kline, 1986; Anastasi \& Urbina, 1998; Santisteban, 2009; Furr \& Bacharach, 2008), lo cual garantiza la calidad de los datos de la investigación y la posibilidad de alcanzar resultados relevantes.

Por otro lado, con relación al inventario de estrategias de aprendizaje y de estudio (IEAE), en el cual se construyó una forma corta, los hallazgos psicométricos alcanzados son consistentes con los hallazgos presentados en los

Tabla 13

Correlaciones entre los hábitos de consumo de plataformas en línea y la aplicación de estrategias de aprendizaje y estudio

\begin{tabular}{lc}
\hline Variables & $\begin{array}{c}\text { Hábitos de consumo } \\
\text { de plataformas en línea } \\
r_{s}\end{array}$ \\
\hline Actitud & -0.08 \\
Motivación & $0.21^{* *}$ \\
Administración del tiempo & 0.04 \\
Ansiedad & $0.17^{* *}$ \\
Concentración & $0.21^{* *}$ \\
Procesamiento de información & $-0.22^{* *}$ \\
Detección de ideas principales & 0.07 \\
Ayudas para el estudio & $-0.28 * * *$ \\
Autoevaluación & $-0.29^{* * *}$ \\
Estrategia para el examen & $0.17^{* *}$ \\
\hline $\mathrm{N}=240 \quad{ }^{*} \mathrm{p}<.05{ }^{* *} \mathrm{P}<.01^{* * *} \mathrm{p}<.01$ &
\end{tabular}


estudios realizados por Strucchi (1991), Flowers (2003) y Escurra (2006).

Con relación al análisis de la plataforma Facebook se corroboró que es la plataforma en línea más usada por los estudiantes universitarios, lo cual concuerda con lo reportado por Boyd (2007), dado que en el estudio el $86 \%$ de la muestra presenta una antigüedad mayor de un año en el uso de la plataforma, a la vez que reportan una frecuencia de uso diario de más de una hora en el 79,3\%. Además, se puede apreciar que cuando los estudiantes utilizan la computadora, mantienen abierta la red social Facebook en el 84,2 \% de los casos. Lo cual sería indicativo de que son estudiantes que ya poseen una experiencia considerable de uso de dicha plataforma, la cual estaría ejerciendo una relativa influencia en su forma de pensar y procesar la información, lo cual concuerda con lo establecido por Vigotsky (en Monereo \& Pozo, 2008) y Carr (2011), quienes planteaban que las herramientas que usamos modifican nuestros hábitos $\mathrm{y}$, por consiguiente, nuestras mentes.

El uso que más se le da a Facebook es el de mantenerse en contacto y comunicarse con el círculo de amigos y familiares en más del $65 \%$ de los casos, siendo el objetivo de este contacto el intercambio de información. Este hallazgo se corresponde con lo establecido por Dancker (1990) y Slovic (1987), quienes conceptualizan a las nuevas tecnologías como instrumentos amiga- bles, de bajo riesgo y ligadas a la comunicación e intercambio de información.

Un elemento a favor de Facebook es que el $63,5 \%$ considera a la red como atractiva o muy atractiva, lo cual se explica por el hecho de que los jóvenes evalúan la calidad de las páginas web no en relación con su contenido, sino a su diseño y posibilidad de interactividad, tal como sugiere Livingstone (2009). Esto se relaciona con el hallazgo de que Facebook es percibida como una plataforma que posee una facilidad alta o muy alta de manejo, en un $54,5 \%$. La atracción también se conecta con el hecho de que Facebook es una plataforma que permite que los usuarios se concentren en los elementos que llaman su atención frecuentemente y siempre en un $43,2 \%$. El número de elementos que llaman la atención de los usuarios son de dos a más en el $65 \%$ de los casos.

Otro aspecto interesante que ha sido observado es que Facebook no concita solo la atención, sino que el 84,2 \% reporta tener abierta por lo menos una ventana adicional diferente. Esto reflejaría que en los alumnos se estaría fomentando el uso de la atención dividida tal como lo indican Lalueza, Crespo \& Camps (2008). Adicionalmente, el que los alumnos declaren que utilizan esta plataforma sin ver otro programa o realizar otra tarea en 10 minutos o menos en el $39,3 \%$ de los casos implica que los periodos de uso efectivo tenderían a ser bastante cortos. Por consiguiente, el uso de Facebook estaría promoviendo una 
menor concentración y un procesamiento superficial de los estímulos que son procesados por el usuario, lo cual coincide con lo reportado por Carr (2011), quien plantea que internet fomenta una menor duración de la atención.

Respecto del análisis de la plataforma YouTube, el 74,1 \% presenta una antigüedad mayor a los tres años en el uso de la plataforma, a la vez que reportan una frecuencia de uso diario de más de una hora en el 63,5\% de los casos. También se debe señalar que el $55,7 \%$ de los casos mantiene normalmente abierto el YouTube cuando utiliza la computadora. Lo anterior señalaría que la muestra posee una experiencia considerable en el uso de la plataforma YouTube, por lo que esta estaría también influenciando su forma de pensar y procesar la información, lo cual concuerda con el punto de vista indicado anteriormente por Vigotsky (en Monereo \& Pozo, 2008).

En relación con la atención puesta en el uso de YouTube, el 94,8 \% declara tener de dos a más ventanas abiertas de otros programas, esto permitiría inferir que, al igual que en el Facebook, se estaría promoviendo el uso de la atención dividida (Lalueza, Crespo \& Camps, 2008); con sus consiguientes efectos negativos, tal como los sugiere la perspectiva de los recursos atencionales limitados propuesta por Kahneman (en Sternberg, 2011), quien resalta la dificultad para realizar dos o más tareas complejas simultáneas, es decir el uso de las plataformas en línea podría estar interfiriendo en el desarrollo de la actividad académica más compleja y, por ende, en un mejor rendimiento de los estudiantes.

Por otra parte, el 47,5\% de la muestra declara que utiliza YouTube sin ver otro programa o realizar otra tarea hasta un máximo de 10 minutos o menos. Por consiguiente, se podría inferir que los periodos de uso efectivo de YouTube tenderían a ser reducidos, promoviendo, de esta manera, una menor concentración en los estímulos y un procesamiento superficial de estos, lo que concuerda con los hallazgos de Carr (2011).

Respecto a la primera hipótesis los hallazgos indican que la plataforma en línea Facebook es la más utilizada de forma significativa entre los estudiantes evaluados, puesto que fomenta la comunicación entre sus usuarios y el fortalecimiento de los lazos sociales, lo cual coincide con lo planteado por Livingstone (2009) cuando sostiene que una de las características por las que se prefiere un producto en línea es por la posibilidad que brinda de interactuar con los demás. Adicionalmente, esta preferencia por dicha red social se explicaría de acuerdo con lo propuesto por Ruiz (2006), quien concluye que las redes sociales fortalecen el autoconcepto de sus usuarios, pues dicho constructo social implica la validación y retroinformación de los demás.

En la hipótesis 2 los resultados muestran que tanto en la escala total como en la de conocimientos y la de 
regulación predominan los niveles bajos de desarrollo, lo cual indicaría que mayoritariamente los estudiantes tienen un bajo nivel de desarrollo en el conocimiento de sus metacogniciones en el contexto académico. Es decir, un limitado conocimiento de aquello que el alumno necesita saber antes de procesar y evaluar un determinado tema: no conoce sus propias habilidades, ni sus recursos intelectuales como estudiante. Por otro lado, al tener los estudiantes un déficit en la regulación presentan dificultades en la forma como se planifican, organizan, identifican y depuran aquellas estrategias en el contexto del aprendizaje académico. De manera que, potencialmente, su rendimiento académico estaría disminuido, tal como lo proponen Mayor, Suengas y GonzálezMárquez (1993).

En el análisis de la tercera hipótesis, referido al estudio de las estrategias metacognitivas de la lectura, los hallazgos indican que en la escala total, la estrategia global, la estrategia de solución de problemas y las estrategias de apoyo a la lectura predominan de manera significativa bajos niveles de desarrollo. Este hallazgo refleja que los alumnos presentarían deficiencias durante el proceso de lectura académica, lo cual se expresaría en dificultades para analizar un texto de forma general estableciendo sus características. Asimismo, cuando el texto es de mayor dificultad presentarían problemas para poder superarlas y obtener una adecuada comprensión lecto- ra. Además, los estudiantes encuentran dificultades para utilizar materiales de estrategias de referencia cuando leen, como tomar notas, hacer esquemas y usar otros procedimientos prácticos. Todo ello redundaría negativamente en su desempeño lector (Mokhtari \& Reichard, 2002), así como en la existencia de lectores léxicos, quienes tienen una comprensión fragmentada, no holística de lo que leen, tal como lo propone Gonzales (1998).

En la hipótesis 4 los resultados alcanzados indican que los estudiantes presentan un nivel alto de desarrollo en la actitud hacia el estudio, esto indicaría que existirían una adecuada valoración e interés por la universidad y el éxito académico. Por el contrario, los aspectos menos desarrollados corresponden a la motivación, entendida como la baja disposición a realizar el esfuerzo necesario para lograr o superar los retos académicos. Otro aspecto poco desarrollado es el procesamiento de la información, que indicaría que los estudiantes usan de forma limitada su imaginación, elaboraciones verbales, estrategias de organización, habilidades de razonamiento y habilidades para aprender las estrategias para ayudar al aprendizaje. También se aprecia un nivel bajo en el desarrollo para utilizar ayudas en el estudio, es decir que la muestra presenta un inadecuado uso de técnicas de apoyo o uso de materiales o recursos para aprender o para recordar la nueva información, hallazgos que concuerdan 
en parte con lo reportado por Escurra (2006).

Al analizar la hipótesis 5, la misma que evalúa la relación entre los hábitos de consumo de plataformas en línea y la conciencia metacognitiva, los resultados alcanzados indican que existen correlaciones negativas significativas y moderadas entre los hábitos de consumo de plataformas en línea, el total de la conciencia metacognitiva y la regulación. Estos hallazgos indicarían la presencia de una relación negativa, es decir que cuando más intensos sean los hábitos de consumo de las plataformas en línea, los estudiantes tenderán a mostrar una menor regulación de la cognición: planificarían menos, utilizarían poco sus estrategias de gestión de conocimientos y harían un menor seguimiento de sus aprendizajes en las tareas. Estos hallazgos podrían deberse a que el uso constante de las plataformas en línea se conecta con efectos inmediatos, vale decir, se tiene la necesidad de una rápida retroinformación con escasa elaboración del usuario (Lalueza, Crespo \& Camps, 2008). La necesidad de lo inmediato y la impaciencia por la retroinformación contrasta con los procesos metacognitivos que están relacionados con el monitoreo de las actividades y la reflexión sobre estas, las que dan fruto, generalmente, en el mediado y largo plazo. Es importante recordar que la reflexión, el monitoreo y la paciencia para comprender los contenidos que se procesan son aspectos primordiales de la vida universitaria (Mayor, Suengas \& Gonzales-Márquez, 1993).

En relación con la hipótesis 6 , en la cual se analiza la relación entre los hábitos de consumo de plataformas en línea y las estrategias metacognitivas de la lectura, los hallazgos indicaron que existían correlaciones bajas, lo cual indicaría una relativa independencia entre ambos aspectos, de manera que no es factible hablar de la presencia de una relación relevante.

En el caso de la hipótesis 7, en la que se relacionan los hábitos de consumo de las plataformas en línea y las estrategias de aprendizaje, tampoco se pudieron obtener relaciones significativas, por lo cual también se notaría una relativa independencia de las dos variables analizadas.

En líneas generales, en estas dos últimas hipótesis se puede notar que los hábitos de uso de plataformas en línea solo reflejan relaciones negativas moderadas con los aspectos más cognitivos de la vida universitaria, como es el caso de la conciencia metacognitiva y una relación menor con los aspectos más pragmáticos, como es el caso de las estrategias metacognitivas en la lectura y las estrategias de aprendizaje y estudio. Por lo cual, de acuerdo con Carr (2011), sería pertinente, en un futuro cercano, tratar de corroborar los hallazgos alcanzados con respecto a la vida académica. 
CONCLUSIONES Y RECOMENDACIONES

\section{Conclusiones}

El estudio concluye que los estudiantes universitarios presentan:

- Un elevado uso de la plataforma en línea Facebook.

- Un bajo nivel de desarrollo en la conciencia metacognitiva, tanto en la evaluación total como en las áreas de conocimientos y regulación.

- Un bajo nivel de desarrollo de estrategias metacognitivas en la lectura. Esto ocurre tanto en la medición total como en la estrategia global, la estrategia de solución de problemas y la estrategia de apoyo a la lectura.

- Un elevado desarrollo de las estrategias de aprendizaje y estudio en el área de la actitud.

- Un nivel de desarrollo medio en las estrategias de aprendizaje y estudio en las áreas de la administración del tiempo, la ansiedad, la concentración, la detección de ideas principales, la autoevaluación y las estrategias para rendir un examen.

- Un nivel de desarrollo bajo en las estrategias de aprendizaje en las áreas de procesamiento de la información y uso de ayudas para el estudio.

- Una relación significativa negativa y moderada entre los hábitos de consumo de las plataformas en línea y la conciencia metacognitiva; esto ocurre tanto en la evaluación total como en el área de regulación.

- Una relación significativa negativa y baja entre los hábitos de consumo de las plataformas en línea y las estrategias metacognitivas en la lectura.

- Relaciones negativas significativas y bajas entre los hábitos de consumo de las plataformas en línea y las estrategias de aprendizaje y estudio.

\section{Recomendaciones}

- Replicar el estudio con muestras de alumnos universitarios tanto de precomo de posgrado.

- Desarrollar estudios incorporando nuevos constructos, como el rendimiento académico, el desempeño en la lectura, la autoeficacia y el síndrome de atención deficitaria, entre otros.

- Elaborar programas que fomenten diferentes habilidades para la vida universitaria; por ejemplo, el desarrollo de una atención extendida, la aplicación de estrategias para la lectura universitaria y de desarrollo metacognitivo.

- Realizar estudios comparativos acerca de la temática propuesta con estudiantes universitarios usuarios y no usuarios de las plataformas en línea.

- Desarrollar programas de capacitación que utilicen las nuevas tecnologías para acercar al alumno al 
conocimiento universitario relacionado con la investigación científica; por ejemplo, el uso de buscadores académicos, la utilización de bases de datos científicas en línea y de software especializado de investigación. Este tipo de programas debe tener la finalidad de fomentar hábitos académicos.

- Desarrollar aplicaciones alternativas para el contexto académico de las plataformas en línea Facebook y YouTube.

\section{REFERENCIAS}

Anastasi, A., \& Urbina, S. (1998). Test psicológicos. México: Prentice Hall.

Boyd, D. (2007). Why youth (heart) social network sites: The role of networked publics in teenage social life. MacArthur Foundation Series on Digital Learning-Youth, Identity, and Digital Media Volume (David Buckingham, ed.). Cambridge, MA: MIT Press.

Carr, P. (2010). The shallows. What the internet is doing to our brains. Nueva York: Norton \& Company.

Castañeda, L. (2010). Aprendizaje con redes sociales. Tejidos educativos para nuevos entornos. Bogotá: Ediciones de la U.

Cebrián, M. (2011). Los centros educativos en la sociedad de la información y el conocimiento. En: M. Cebrián. Procesos educativos con TIC en la sociedad del conocimiento (23-31). Madrid: Pirámide.

Chau, C. (2010). Youtube as a participatory culture. New Directions for Youth Develpment, 65-74.

Dancker, D.; Ivo, A., \& Cees, J. (1990). Cognitives structures in the perception of modern technologies. Science, Technology, \& Human Values, Vol. 15(2), 202-225.

Escurra, L. M. (2006). Análisis psicométrico del inventario de estrategias de aprendizaje y estudio en estudiantes universitarios de Psicología de Lima metropolitana. Persona, 9, 127-170.

Flavell, J. (1979). Metacognición and cognitive monitoring: A new area if cognitive inquiry. American Psychologist, 34(10), 906-911.

Flowers, L. (2003). Test-retest reliability of the learning and study strategies inventori (LASSI). Reading Research and Instructions, 43(1), 31-46.

Furr, R. N., \& Bacharach, B. R. (2008). Psichometrics and introduction. Thousands Oaks, CA: Sage.

Gonzales Moreyra, R. (1998). Comprensión lectora en estudiantes universitarios iniciales. Persona, 1 , 43-65.

Haught, P. A., Hill, L. A., Walls, R. T., \& Nardi, A. H. (1998). Improved learning and study strategies inven- 
tory (LASSI) and academic performance: The impact of feedback on freshmen. Journal of The First-Year Experience, 10(2), 25-40.

Hernández, S. R., Fernández, C. C., \& Baptista, L. P. (2010). Metodología de la Investigación. México, D. F.: MacGraw-Hill.

Junco, R., \& Cotten, Sh. (2011). A decade of distraction? How multitasking affects students outcomes. A decade in internet time symposium on the dynamics of the internet and society, (1-33). Oxford: Oxford Internet Institute.

Kahneman, D. (2011). Thinking fast and slow. Nueva York: Farrar, Strauss \& Giroux.

Kline, P. (1986). A handbook of test construction: Introduction to psychometric design. Londres: Methuen.

Kurtz-Costes, B. E., \& Schneider, W. (1994). Self-concept, attributional beliefs, and school achievement: a longitudinal analysis. Contemporary Educational Psychology, 19, 199-216.

Lalueza, J. L., Crespo, I., \& Camps, S. (2008). Las tecnologías de la información y la comunicación y los procesos de desarrollo y socialización. En: Coll, C. \& Monereo, C. (eds.). Psicología de la educación virtual. Madrid: Ediciones Morata SL.
Livingstone, S. (2009). Children and the internet. Cambridge: Polity Press.

Lohr, S. L. (2000). Muestreo: diseño $y$ análisis: México: International Thomson editores.

Mayor, J., Suengas, A., \& GonzálezMárquez, J. (1993). Estrategias metacognitivas. Aprender a aprender y aprender a pensar. Madrid: Síntesis.

McNamara, D. (2009). The importance of teaching reading stratategies. Perspectives on Language and Literacy. ProQuest Central, 35-40.

Mokhtari, K., \& Reichard, C. A. (2002). Assesing students metacognitive awareness of reading strategies. Journal of Educational Psychology, 94(2), 249-259. DOI: 10.1037//00220663.94.2.249.

Monereo, C., \& Pozo, J. (2008). El alumno en entornos virtuales: Condiciones, perfil y competencias. En: Coll, C., \& Monereo, C. (eds.). Psicología de la educación virtual (109-131). Madrid: Morata.

Pintrich, P. \& de Groot, E. V. (1990). Motivational and self regulated learning components of classroom academic performance. Journal of Educational Psychology, 82(1), 33-40.

Pozo, J. (1996). Aprendices y maestros: la nueva cultura del aprendizaje. Madrid: Alianza Editorial. 
Reátegui, N. \& Satter, C. (1996). Metacognición: Estrategias para la construcción del conocimiento. Lima: Centro Psicosocial de Desarrollo Humano.

Ruiz, F. (2006). Fortaleciendo el autoconcepto. El uso de las formas de comunicación en Internet. Teoría e Investigación en Psicología, 16, $33-42$.

Santisteban, C. (2009). Principios de psicometría. Madrid: Síntesis.

Schmar-Dobler, E. (2003). Reading on the Internet: The link between literacy and technology. Journal of adolescent \& adult literacy. ProQuest Central, 80-85.

Sheldon, P. (2008). The relationship between unwillingness to comunicate and students Facebook use. Journal of Media Psychology, 20(2), 6775. DOI: 10.1027/1864-1105.20.2.67.

Siegel, S., \& Castellán, N. J. (1995). Estadísticas no paramétricas apli- cadas a las ciencias de la conducta. México, D. F.: Trillas.

Sternberg, R. (2011). Atención y conciencia. En: Sternberg, R. Psicología cognoscitiva (152-159). México, D. F.: Cengace Learning.

Strucchi, E. (1991). LASSI: Inventario de estrategias de aprendizaje $y$ estudio. Buenos Aires: Psicoteca Editorial.

Wallace, P. (2001). Psicología del internet. Barcelona: Paidós.

Weinstein, C., \& Mayer, R. (1986). The teaching of learning strategies. En: Wittrock, M. (ed.). Handbook of research on teaching. Nueva York: Macmillan.

Woolfolk, A. (2010). Psicología educativa. Naucalpan de Juárez: Pearson.

Yoo, H. et al. (2004). Attention deficit hyperactivity symptoms and Internet addiction. Psychiatry and Clinical Neurosciences, 58(5), 487-494. 


\section{ANEXOS}

Edad: años

Sexo: 1 Masculino

$2 \quad$ Femenino

Universidad:

Año de ingreso a la universidad:

Carrera que estudia:

Ciclo de estudio:

La forma de marcar su(s) respuesta(s), es realizando un círculo alrededor del número que coincida con su opinión.

1) ¿Qué productos en línea usa de manera habitual? 1 Facebook

2 YouTube

2) Según su parecer ponga en orden de importancia a los siguientes productos online: Facebook, YouTube

$1 .{ }^{\circ}$ $2 .^{\circ}$

3) ¿Desde cuándo usa Facebook?

1 Menos de un año 2 Un año 3 Dos años 4 Tres años 5 De cuatro años a más

4) ¿Desde cuándo usa YouTube?

1 Menos de un año 2 Un año 3 Dos años 4 Tres años 5 De cuatro años a más

5) Frecuencia de uso diario de Facebook
1 Menos de una hora
3 De 2 a tres horas
5 Más de 4 horas
2 De 1 a 2 horas
4 De 3 a 4 horas

6) Frecuencia de uso diario de YouTube
1 Menos de una hora
3 De 2 a tres horas
5 Más de 4 horas
2 De 1 a 2 horas
4 De 3 a 4 horas

Marque con un círculo todas las opciones que considere convenientes:

7) Usted utiliza el Facebook para:

1. Intercambio de información

2. Dar/recibir apoyo social

3. Conocer nuevas personas

4. Estrechar amistad con conocidos

5. Realizar tareas académicas

6. Mantenerse en contacto con su círculo social de amigos y familiares

7. Comunicarse con su círculo social de amigos y familiares

8. Saber qué están haciendo mis amigos y familiares

9. Entretenimiento

10. Estar al tanto de lo que ocurre en el mundo

11. Estar al tanto de lo que ocurre en su círculo social 
8) Usted utiliza el YouTube para:

1. Intercambio de información

2. Realizar tareas académicas

3. Entretenimiento

4. Estar al tanto de lo que ocurre en el mundo

9) Cuando utiliza la computadora, normalmente mantiene abierto el Facebook:
1 Sí
2 No

10)Si la respuesta en $P 9$ es afirmativa: ¿Cuántas ventanas tiene abiertas además de Facebook?
1 Una más
2 Dos más
3 Tres más
4 Cuatro más
5 Cinco más

11) En promedio, usted utiliza el Facebook sin ver otro programa o realizar otra tarea en periodos de...:
1 Menos de 5 minutos
310 a 15 minutos
5 Más de 20 minutos
25 a 10 minutos
415 a 20 minutos

12) Cuando utiliza la computadora, normalmente mantiene abierto el YouTube:

1 Sí 2 No

13) Si la respuesta en P12 es afirmativa: ¿Cuántas ventanas tiene abiertas además de YouTube?
1 Una más
2 Dos más
3 Tres más
4 Cuatro más
5 Cinco más

14) En promedio, usted utiliza el YouTube sin ver otro programa o realizar otra tarea en periodos de:
1 Menos de 5 minutos
310 a 15 minutos
5 Más de 20 minutos
25 a 10 minutos
415 a 20 minutos

15) ¿Cómo calificaría la manera en que están presentados los elementos de Facebook?
1 Nada atractiva
3 Más o menos atractiva
5 Muy atractiva
2 Poco atractiva
4 Atractiva

16) ¿Cómo calificaría la manera en que están presentados los elementos de YouTube?
1 Nada atractiva
3 Más o menos atractiva
5 Muy atractiva
2 Poco atractiva
4 Atractiva

17) ¿Cómo calificaría la facilidad de manejo de Facebook?
1 Muy baja
2 Baja
3 Intermedia
4 Alta
5 Muy alta

18) ¿Cómo calificaría la facilidad de manejo de YouTube?
1 Muy baja
2 Baja
3 Intermedia
4 Alta
5 Muy alta

19) Usted revisa el Facebook de manera ordenada (de izquierda a derecha, de arriba abajo)
1 Siempre
2 Frecuentemente
3 A veces
4 Casi nunca
5 Nunca 
20) Usted revisa el Facebook sin seguir un orden en particular, centrándose en lo que llame su atención.
1 Nunca
2 Casi nunca
3 A veces
4 Frecuentemente
5 Siempre

21) Usted revisa el YouTube de manera ordenada (de izquierda a derecha, de arriba abajo)
1 Siempre
2 Frecuentemente
3 A veces
4 Casi nunca
5 Nunca

22) Usted revisa el YouTube sin seguir un orden en particular, centrándose en lo que llame su atención.
1 Nunca
2 Casi nunca
3 A veces
4 Frecuentemente
5 Siempre

23) Cuando usted revisa Facebook:

1 Examina un elemento a la vez

2 Examina de dos a tres elementos a la vez

3 Examina de tres a cuatro elementos a la vez

4 Examina de cuatro a cinco elementos a la vez

5 Examina más de cinco elementos a la vez

(Por elemento se entiende: correo, post, wall, comentarios, etc.)

24) Cuando usted revisa YouTube

1 Examina un elemento a la vez

2 Examina de dos a tres elementos a la vez

3 Examina de tres a cuatro elementos a la vez

4 Examina de cuatro a cinco elementos a la vez

5 Examina más de cinco elementos a la vez

(Por elemento se entiende: comentarios, videos, videos sugeridos, etc.) 


\section{Inventario de conciencia metacognitiva - $\mathbf{R}$}

\section{INSTRUCCIONES}

A continuación se presenta un conjunto de enunciados que están referidos a diferentes aspectos relacionados con su actividad universitaria en general. Ud. debe indicar lo que corresponde sobre lo indicado en cada frase, realizando un círculo en una de las 5 opciones presentadas, de modo que indique con la mayor exactitud posible lo que siente y piensa.

\begin{tabular}{|c|c|c|c|c|c|c|}
\hline $\mathbf{N}$ & Enunciados & $\begin{array}{l}\text { Siempre } \\
\text { lo hago }\end{array}$ & $\begin{array}{l}\text { Frecuen- } \\
\text { temente lo } \\
\text { hago }\end{array}$ & $\begin{array}{l}\text { A veces } \\
\text { lo hago }\end{array}$ & $\begin{array}{c}\text { Casi } \\
\text { nunca } \\
\text { lo hago }\end{array}$ & $\begin{array}{l}\text { Nunca } \\
\text { lo } \\
\text { hago }\end{array}$ \\
\hline 1 & $\begin{array}{l}\text { Trato de usar las estrategias que me han } \\
\text { funcionado anteriormente en el pasado }\end{array}$ & 1 & 2 & 3 & 4 & 5 \\
\hline 2 & $\begin{array}{l}\text { Cuando estudio tomo en cuenta mi ritmo } \\
\text { de aprendizaje con el fin de tener tiempo } \\
\text { suficiente }\end{array}$ & 1 & 2 & 3 & 4 & 5 \\
\hline 3 & $\begin{array}{l}\text { Identifico cuales son mis fortalezas y } \\
\text { debilidades intelectuales }\end{array}$ & 1 & 2 & 3 & 4 & 5 \\
\hline 4 & $\begin{array}{l}\text { Cuando estudio sé qué estrategia de } \\
\text { aprendizaje debo usar }\end{array}$ & 1 & 2 & 3 & 4 & 5 \\
\hline 5 & $\begin{array}{l}\text { Aprendo mejor cuando sé algo sobre el } \\
\text { tema }\end{array}$ & 1 & 2 & 3 & 4 & 5 \\
\hline 6 & Soy bueno para recordar la información & 1 & 2 & 3 & 4 & 5 \\
\hline 7 & $\begin{array}{l}\text { Puedo utilizar diferentes estrategias de } \\
\text { aprendizaje en función de la situación }\end{array}$ & 1 & 2 & 3 & 4 & 5 \\
\hline 8 & $\begin{array}{l}\text { Me pregunto si había una manera más } \\
\text { fácil de hacer las cosas después de } \\
\text { terminar una tarea }\end{array}$ & 1 & 2 & 3 & 4 & 5 \\
\hline 9 & $\begin{array}{l}\text { Tengo control sobre lo bien que puedo } \\
\text { aprender }\end{array}$ & 1 & 2 & 3 & 4 & 5 \\
\hline 10 & $\begin{array}{l}\text { Reviso periódicamente la información } \\
\text { para ayudarme a entender las relaciones } \\
\text { importantes }\end{array}$ & 1 & 2 & 3 & 4 & 5 \\
\hline 11 & $\begin{array}{l}\text { Me hago preguntas sobre el material } \\
\text { antes de empezar a estudiar }\end{array}$ & 1 & 2 & 3 & 4 & 5 \\
\hline 12 & $\begin{array}{l}\text { Pido ayuda a los demás cuando no } \\
\text { entiendo algo }\end{array}$ & 1 & 2 & 3 & 4 & 5 \\
\hline 13 & $\begin{array}{l}\text { Puedo motivarme para aprender cuando } \\
\text { lo necesito }\end{array}$ & 1 & 2 & 3 & 4 & 5 \\
\hline
\end{tabular}


(continuación)

\begin{tabular}{|c|c|c|c|c|c|c|}
\hline $\mathbf{N}$ & Enunciados & $\begin{array}{l}\text { Siempre } \\
\text { lo hago }\end{array}$ & $\begin{array}{l}\text { Frecuen- } \\
\text { temente lo } \\
\text { hago }\end{array}$ & $\begin{array}{l}\text { A veces } \\
\text { lo hago }\end{array}$ & $\begin{array}{c}\text { Casi } \\
\text { nunca } \\
\text { lo hago }\end{array}$ & $\begin{array}{c}\text { Nunca } \\
\text { lo } \\
\text { hago }\end{array}$ \\
\hline 14 & $\begin{array}{l}\text { Soy consciente de las estrategias que } \\
\text { utilizo cuando estudio }\end{array}$ & 1 & 2 & 3 & 4 & 5 \\
\hline 15 & $\begin{array}{l}\text { Analizo la utilidad de las estrategias que } \\
\text { utilizo mientras estudio }\end{array}$ & 1 & 2 & 3 & 4 & 5 \\
\hline 16 & $\begin{array}{l}\text { Me concentro en el significado y la } \\
\text { importancia de la nueva información }\end{array}$ & 1 & 2 & 3 & 4 & 5 \\
\hline 17 & $\begin{array}{l}\text { Puedo crear mis propios ejemplos para } \\
\text { hacer la información más comprensible }\end{array}$ & 1 & 2 & 3 & 4 & 5 \\
\hline 18 & $\begin{array}{l}\text { Soy un buen juez de lo bien que entiendo } \\
\text { algo }\end{array}$ & 1 & 2 & 3 & 4 & 5 \\
\hline 19 & $\begin{array}{l}\text { Cuando estudio me ayudo con las } \\
\text { estrategias de aprendizaje de forma } \\
\text { rápida }\end{array}$ & 1 & 2 & 3 & 4 & 5 \\
\hline 20 & $\begin{array}{l}\text { Hago una pausa con regularidad para } \\
\text { revisar si comprendo los temas }\end{array}$ & 1 & 2 & 3 & 4 & 5 \\
\hline 21 & $\begin{array}{l}\text { Puedo identificar la estrategia que debo } \\
\text { aplicar para ser más eficaz en lo que } \\
\text { realizo }\end{array}$ & 1 & 2 & 3 & 4 & 5 \\
\hline 22 & $\begin{array}{l}\text { Me pregunto qué tan bien he logrado } \\
\text { mis metas una vez que he terminado }\end{array}$ & 1 & 2 & 3 & 4 & 5 \\
\hline 23 & $\begin{array}{l}\text { Me pregunto si he considerado todas } \\
\text { las opciones después de resolver un } \\
\text { problema }\end{array}$ & 1 & 2 & 3 & 4 & 5 \\
\hline 24 & $\begin{array}{l}\text { Trato de traducir la información nueva } \\
\text { en mis propias palabras }\end{array}$ & 1 & 2 & 3 & 4 & 5 \\
\hline 25 & $\begin{array}{l}\text { Uso la estructura organizativa del texto } \\
\text { para que me ayude a comprender lo que } \\
\text { leo }\end{array}$ & 1 & 2 & 3 & 4 & 5 \\
\hline 26 & $\begin{array}{l}\text { Leo atentamente las instrucciones antes } \\
\text { de comenzar una tarea }\end{array}$ & 1 & 2 & 3 & 4 & 5 \\
\hline 27 & $\begin{array}{l}\text { Trato de reevaluar mis suposiciones } \\
\text { cuando me confundo }\end{array}$ & 1 & 2 & 3 & 4 & 5 \\
\hline 28 & $\begin{array}{l}\text { Organizo mi tiempo para lograr mejor } \\
\text { mis metas }\end{array}$ & 1 & 2 & 3 & 4 & 5 \\
\hline 29 & $\begin{array}{l}\text { Me hago preguntas acerca de lo bien } \\
\text { que estoy haciendo las cosas, mientras } \\
\text { estoy aprendiendo algo nuevo }\end{array}$ & 1 & 2 & 3 & 4 & 5 \\
\hline
\end{tabular}




\begin{tabular}{|c|c|c|c|c|c|c|}
\hline $\mathbf{N}$ & Enunciados & $\begin{array}{l}\text { Siempre } \\
\text { lo hago }\end{array}$ & $\begin{array}{l}\text { Frecuen- } \\
\text { temente lo } \\
\text { hago }\end{array}$ & $\begin{array}{l}\text { A veces } \\
\text { lo hago }\end{array}$ & $\begin{array}{l}\text { Casi } \\
\text { nunca } \\
\text { lo hago }\end{array}$ & $\begin{array}{c}\text { Nunca } \\
\text { lo } \\
\text { hago }\end{array}$ \\
\hline 30 & $\begin{array}{l}\text { Me pregunto si he aprendido de acuerdo } \\
\text { con mis capacidades }\end{array}$ & 1 & 2 & 3 & 4 & 5 \\
\hline 31 & $\begin{array}{l}\text { Me detengo y trato de volver sobre la } \\
\text { nueva información que no queda clara }\end{array}$ & 1 & 2 & 3 & 4 & 5 \\
\hline 32 & $\begin{array}{l}\text { Me detengo a volver a leer el material } \\
\text { cuando me siento confundido }\end{array}$ & 1 & 2 & 3 & 4 & 5 \\
\hline 33 & $\begin{array}{l}\text { Tomo apuntes cuando leo para } \\
\text { ayudarme a entender lo que leo }\end{array}$ & 1 & 2 & 3 & 4 & 5 \\
\hline 34 & $\begin{array}{l}\text { Pienso en lo que sé para ayudarme a } \\
\text { entender lo que leo }\end{array}$ & 1 & 2 & 3 & 4 & 5 \\
\hline 35 & $\begin{array}{l}\text { Cuando el texto se hace difícil, leo en } \\
\text { voz alta para ayudarme a entender lo } \\
\text { que estoy leyendo }\end{array}$ & 1 & 2 & 3 & 4 & 5 \\
\hline 36 & $\begin{array}{l}\text { Resumo lo que leo para reflexionar } \\
\text { sobre la información importante en el } \\
\text { texto }\end{array}$ & 1 & 2 & 3 & 4 & 5 \\
\hline 37 & $\begin{array}{l}\text { Leo despacio, pero con cuidado para } \\
\text { estar seguro de que entiendo lo que } \\
\text { estoy leyendo }\end{array}$ & 1 & 2 & 3 & 4 & 5 \\
\hline 38 & $\begin{array}{l}\text { Hablo acerca de lo que leo con otros } \\
\text { para comprobar mi comprensión }\end{array}$ & 1 & 2 & 3 & 4 & 5 \\
\hline 39 & $\begin{array}{l}\text { Subrayo la información en el texto para } \\
\text { ayudarme a recordarlo }\end{array}$ & 1 & 2 & 3 & 4 & 5 \\
\hline 40 & $\begin{array}{l}\text { Adecúo mi velocidad de lectura según lo } \\
\text { que leo }\end{array}$ & 1 & 2 & 3 & 4 & 5 \\
\hline 41 & $\begin{array}{l}\text { Cuando el texto se hace difícil, le pongo } \\
\text { más atención a lo que leo }\end{array}$ & 1 & 2 & 3 & 4 & 5 \\
\hline 42 & $\begin{array}{l}\text { Utilizo las tablas, figuras y cuadros del } \\
\text { texto para aumentar mi comprensión }\end{array}$ & 1 & 2 & 3 & 4 & 5 \\
\hline 43 & $\begin{array}{l}\text { Me detengo cada cierto tiempo para } \\
\text { pensar en lo que leo }\end{array}$ & 1 & 2 & 3 & 4 & 5 \\
\hline 44 & $\begin{array}{l}\text { Uso las pistas del contexto para } \\
\text { ayudarme a entender mejor lo que leo }\end{array}$ & 1 & 2 & 3 & 4 & 5 \\
\hline 45 & $\begin{array}{l}\text { Analizo en profundidad y evalúo la } \\
\text { información presentada en el texto }\end{array}$ & 1 & 2 & 3 & 4 & 5 \\
\hline 46 & $\begin{array}{l}\text { Compruebo mi comprensión cuando } \\
\text { encuentro por casualidad información } \\
\text { contradictoria }\end{array}$ & 1 & 2 & 3 & 4 & 5 \\
\hline
\end{tabular}


(continuación)

\begin{tabular}{|c|c|c|c|c|c|c|}
\hline $\mathbf{N}$ & Enunciados & $\begin{array}{l}\text { Siempre } \\
\text { lo hago }\end{array}$ & $\begin{array}{l}\text { Frecuen- } \\
\text { temente lo } \\
\text { hago }\end{array}$ & $\begin{array}{l}\text { A veces } \\
\text { lo hago }\end{array}$ & $\begin{array}{c}\text { Casi } \\
\text { nunca } \\
\text { lo hago }\end{array}$ & $\begin{array}{c}\text { Nunca } \\
\text { lo } \\
\text { hago }\end{array}$ \\
\hline 47 & $\begin{array}{l}\text { Cuando el texto se hace difícil, releo } \\
\text { para aumentar mi comprensión }\end{array}$ & 1 & 2 & 3 & 4 & 5 \\
\hline 48 & $\begin{array}{l}\text { Mientras leo, me hago preguntas y trato } \\
\text { de contestarlas con el texto }\end{array}$ & 1 & 2 & 3 & 4 & 5 \\
\hline 49 & $\begin{array}{l}\text { Trato de comprobar si mis conjeturas } \\
\text { sobre el texto son correctas o erradas }\end{array}$ & 1 & 2 & 3 & 4 & 5 \\
\hline 50 & $\begin{array}{l}\text { Trato de adivinar el significado de } \\
\text { palabras desconocidas o frases que hay } \\
\text { en el texto }\end{array}$ & 1 & 2 & 3 & 4 & 5 \\
\hline 51 & $\begin{array}{l}\text { Durante una clase, puedo distinguir } \\
\text { entre la información más importante y la } \\
\text { menos importante }\end{array}$ & 1 & 2 & 3 & 4 & 5 \\
\hline 52 & $\begin{array}{l}\text { Después de clases, reviso mis apuntes } \\
\text { para entender mejor la información }\end{array}$ & 1 & 2 & 3 & 4 & 5 \\
\hline 53 & $\begin{array}{l}\text { Cuando estudio utilizo ayudas } \\
\text { especiales como: subrayar lo más } \\
\text { importante o utilizar claves para resumir }\end{array}$ & 1 & 2 & 3 & 4 & 5 \\
\hline 54 & $\begin{array}{l}\text { Cuando escucho una clase trato de } \\
\text { identificar las ideas principales }\end{array}$ & 1 & 2 & 3 & 4 & 5 \\
\hline 55 & $\begin{array}{l}\text { Cuando estoy estudiando algo que es } \\
\text { aburrido y no me gusta, intento acabarlo }\end{array}$ & 1 & 2 & 3 & 4 & 5 \\
\hline 56 & $\begin{array}{l}\text { Hago lo posible por aprender las } \\
\text { palabras nuevas que surgen de ciertas } \\
\text { situaciones }\end{array}$ & 1 & 2 & 3 & 4 & 5 \\
\hline 57 & $\begin{array}{l}\text { Cuando estudio para una evaluación } \\
\text { pienso en las preguntas que deberían } \\
\text { hacerme }\end{array}$ & 1 & 2 & 3 & 4 & 5 \\
\hline 58 & $\begin{array}{l}\text { Releo mis apuntes antes de ir a la clase } \\
\text { siguiente }\end{array}$ & 1 & 2 & 3 & 4 & 5 \\
\hline 59 & $\begin{array}{l}\text { Me esfuerzo en obtener buenas notas } \\
\text { aunque no me guste el curso }\end{array}$ & 1 & 2 & 3 & 4 & 5 \\
\hline 60 & $\begin{array}{l}\text { Tengo la sensación de tener poco } \\
\text { control sobre mis estudios }\end{array}$ & 1 & 2 & 3 & 4 & 5 \\
\hline 61 & $\begin{array}{l}\text { Tengo problemas para planificar el } \\
\text { estudio de un tema; no sé qué pasos } \\
\text { debo seguir }\end{array}$ & 1 & 2 & 3 & 4 & 5 \\
\hline 62 & $\begin{array}{l}\text { Cuando comienzo a rendir un examen, } \\
\text { confío en que me irá bien }\end{array}$ & 1 & 2 & 3 & 4 & 5 \\
\hline
\end{tabular}


(continuación)

\begin{tabular}{|c|c|c|c|c|c|c|}
\hline $\mathbf{N}$ & Enunciados & $\begin{array}{l}\text { Siempre } \\
\text { lo hago }\end{array}$ & $\begin{array}{l}\text { Frecuen- } \\
\text { temente lo } \\
\text { hago }\end{array}$ & $\begin{array}{l}\text { A veces } \\
\text { lo hago }\end{array}$ & $\begin{array}{c}\text { Casi } \\
\text { nunca } \\
\text { lo hago }\end{array}$ & $\begin{array}{c}\text { Nunca } \\
\text { lo } \\
\text { hago }\end{array}$ \\
\hline 63 & $\begin{array}{l}\text { Cuando me pongo a estudiar, las } \\
\text { demoras y las interrupciones me causan } \\
\text { problemas }\end{array}$ & 1 & 2 & 3 & 4 & 5 \\
\hline 64 & $\begin{array}{l}\text { Trato de verificar si comprendo lo que el } \\
\text { profesor dice durante las clases }\end{array}$ & 1 & 2 & 3 & 4 & 5 \\
\hline 65 & $\begin{array}{l}\text { Me interesa poco tener cultura general, } \\
\text { solo deseo conseguir un buen trabajo }\end{array}$ & 1 & 2 & 3 & 4 & 5 \\
\hline 66 & $\begin{array}{l}\text { Trato de relacionar lo que estoy } \\
\text { aprendiendo con lo que ya sabía }\end{array}$ & 1 & 2 & 3 & 4 & 5 \\
\hline 67 & $\begin{array}{l}\text { Siempre que me involucro en estudios } \\
\text { formales, me propongo conseguir } \\
\text { buenos resultados al acabarlos }\end{array}$ & 1 & 2 & 3 & 4 & 5 \\
\hline 68 & $\begin{array}{l}\text { Acabo estudiando con apuros para casi } \\
\text { todas las evaluaciones }\end{array}$ & 1 & 2 & 3 & 4 & 5 \\
\hline 69 & $\begin{array}{l}\text { Me es difícil prestar atención durante las } \\
\text { clases. }\end{array}$ & 1 & 2 & 3 & 4 & 5 \\
\hline 70 & $\begin{array}{l}\text { Cuando leo, señalo de alguna manera } \\
\text { las partes que me interesan }\end{array}$ & 1 & 2 & 3 & 4 & 5 \\
\hline 71 & Solo estudio las materias que me gustan & 1 & 2 & 3 & 4 & 5 \\
\hline 72 & $\begin{array}{l}\text { Intento relacionar lo que estoy } \\
\text { estudiando con mis propias experiencias }\end{array}$ & 1 & 2 & 3 & 4 & 5 \\
\hline 73 & $\begin{array}{l}\text { Hago resúmenes o esquemas para } \\
\text { entender lo que estoy estudiando }\end{array}$ & 1 & 2 & 3 & 4 & 5 \\
\hline 74 & $\begin{array}{l}\text { Me desagrada la mayoría de las } \\
\text { actividades que se hacen en clase }\end{array}$ & 1 & 2 & 3 & 4 & 5 \\
\hline 75 & $\begin{array}{l}\text { Tengo problemas para entender las } \\
\text { preguntas de los exámenes }\end{array}$ & 1 & 2 & 3 & 4 & 5 \\
\hline 76 & $\begin{array}{l}\text { La preocupación por que me pueda ir } \\
\text { mal dificulta mi concentración al dar un } \\
\text { examen }\end{array}$ & 1 & 2 & 3 & 4 & 5 \\
\hline 77 & $\begin{array}{l}\text { Me cuesta entender ciertos temas } \\
\text { porque no presto atención }\end{array}$ & 1 & 2 & 3 & 4 & 5 \\
\hline 78 & Leo los textos que me dan en las clases & 1 & 2 & 3 & 4 & 5 \\
\hline 79 & $\begin{array}{l}\text { Siento pánico al pasar por una } \\
\text { evaluación importante }\end{array}$ & 1 & 2 & 3 & 4 & 5 \\
\hline
\end{tabular}


(continuación)

\begin{tabular}{|c|c|c|c|c|c|c|}
\hline $\mathbf{N}$ & Enunciados & $\begin{array}{l}\text { Siempre } \\
\text { lo hago }\end{array}$ & $\begin{array}{l}\text { Frecuen- } \\
\text { temente lo } \\
\text { hago }\end{array}$ & $\begin{array}{l}\text { A veces } \\
\text { lo hago }\end{array}$ & $\begin{array}{c}\text { Casi } \\
\text { nunca } \\
\text { lo hago }\end{array}$ & $\begin{array}{c}\text { Nunca } \\
\text { lo } \\
\text { hago }\end{array}$ \\
\hline 80 & $\begin{array}{l}\text { Al dar un examen me doy cuenta de que } \\
\text { estudié un tema equivocado }\end{array}$ & 1 & 2 & 3 & 4 & 5 \\
\hline 81 & $\begin{array}{l}\text { Cuando me pongo a estudiar me } \\
\text { concentro totalmente }\end{array}$ & 1 & 2 & 3 & 4 & 5 \\
\hline 82 & $\begin{array}{l}\text { Utilizo los encabezamientos de los } \\
\text { capítulos como guía para encontrar las } \\
\text { ideas más importantes mientras leo }\end{array}$ & 1 & 2 & 3 & 4 & 5 \\
\hline 83 & $\begin{array}{l}\text { Cuando paso por una evaluación me } \\
\text { pongo tan nervioso (a) que no respondo } \\
\text { todo lo que sé }\end{array}$ & 1 & 2 & 3 & 4 & 5 \\
\hline 84 & Dejo de lado el estudio más de lo debido & 1 & 2 & 3 & 4 & 5 \\
\hline 85 & $\begin{array}{l}\text { Mi mente divaga mucho cuando trato de } \\
\text { estudiar }\end{array}$ & 1 & 2 & 3 & 4 & 5 \\
\hline 86 & $\begin{array}{l}\text { Tengo dificultades para adecuar mi } \\
\text { forma de estudiar a las distintas materias }\end{array}$ & 1 & 2 & 3 & 4 & 5 \\
\hline 87 & $\begin{array}{l}\text { Cuando estudio, me pierdo en detalles y } \\
\text { no encuentro las ideas centrales }\end{array}$ & 1 & 2 & 3 & 4 & 5 \\
\hline 88 & $\begin{array}{l}\text { Paso demasiado tiempo con mis amigos } \\
\text { y ello afecta mis estudios }\end{array}$ & 1 & 2 & 3 & 4 & 5 \\
\hline 89 & $\begin{array}{l}\text { Trato de buscar relaciones entre los } \\
\text { distintos temas que estoy estudiando }\end{array}$ & 1 & 2 & 3 & 4 & 5 \\
\hline 90 & $\begin{array}{l}\text { Tengo dificultades para identificar los } \\
\text { puntos importantes en lo que leo }\end{array}$ & 1 & 2 & 3 & 4 & 5 \\
\hline
\end{tabular}

Gracias por su colaboración. 